\title{
Review Article \\ Orthopoxvirus Genes That Mediate Disease Virulence and Host Tropism
}

\author{
Sergei N. Shchelkunov ${ }^{1,2}$ \\ ${ }^{1}$ Department of Genomic Research, State Research Center of Virology and Biotechnology VECTOR, Koltsovo, \\ Novosibirsk Region 630559, Russia \\ ${ }^{2}$ Institute of Cytology and Genetics, Siberian Branch of the Russian Academy of Sciences, Novosibirsk 630090, Russia
}

Correspondence should be addressed to Sergei N. Shchelkunov, snshchel@vector.nsc.ru

Received 24 January 2012; Accepted 31 May 2012

Academic Editor: John Frater

Copyright ( $) 2012$ Sergei N. Shchelkunov. This is an open access article distributed under the Creative Commons Attribution License, which permits unrestricted use, distribution, and reproduction in any medium, provided the original work is properly cited.

In the course of evolution, viruses have developed various molecular mechanisms to evade the defense reactions of the host organism. When understanding the mechanisms used by viruses to overcome manifold defense systems of the animal organism, represented by molecular factors and cells of the immune system, we would not only comprehend better but also discover new patterns of organization and function of these most important reactions directed against infectious agents. Here, study of the orthopoxviruses pathogenic for humans, such as variola (smallpox), monkeypox, cowpox, and vaccinia viruses, may be most important. Analysis of the experimental data, presented in this paper, allows to infer that variola virus and other orthopoxviruses possess an unexampled set of genes whose protein products efficiently modulate the manifold defense mechanisms of the host organisms compared with the viruses from other families.

\section{Introduction}

In the course of evolution, viruses have developed various molecular mechanisms allowing them to evade the host's defense reactions [1-3]. Viruses can become particularly dangerous when they evolve to acquire the possibility to infect new animal species $[4,5]$. The defense systems of the new host may be generally unable to counteract the new pathogen and many individuals will die. In any epidemics, there are also individuals showing little sensitivity or complete resistance to the particular pathogen. Both increased sensitivity and resistance to the infection are specified by the individual's genetic makeup and various environmental factors. Accordingly, mass epidemics not only produce new virus variants but also alter the host population structure: highly sensitive individuals die, while the portion of resistant individuals in the population increases. Therefore, the coevolution of the virus and the host is a mutually dependent process. It should be noted that mutational frequencies that drive genetic variations in viruses are much higher than in mammals [6]. On the other hand, animal genomes contain incomparably higher numbers of genes, while virus resistance mutations usually affect one or, less frequently, several genes. Such mutations may affect virus adsorption on the target cells, its replication, and/or the evasion of the host's defense systems.

Poxviruses are the largest mammalian DNA viruses with the developmental cycle taking place in the cellular cytoplasm [7]. These viruses encode a large set of proteins providing for extranuclear synthesis of virus mRNAs, replication of virus DNA, and assembly of complex virions and are involved in the regulation of multifactorial interactions of the virus with both individual cells and infected host organism. The unique properties of poxviruses attract close attention of researchers. The viruses belonging to the genus Orthopoxvirus are best studied among other viruses of the family Poxviridae, because this genus includes four virus species pathogenic for humans: variola (smallpox) virus (VARV), monkeypox virus (MPXV), cowpox virus (CPXV), and vaccinia virus (VACV). These orthopoxviruses are immunologically cross-reactive and cross-protective, so that infection with any member of this genus provides 
protection against an infection with any other member [3]. An important experimental model is ectromelia virus (mousepox virus, ECTV) $[8,9]$.

VARV causes smallpox and is an exclusively anthroponotic agent. For years, this human pathogen caused epidemics of disease with mortalities of $10-40 \%$. Only the coordinated efforts of the world community, under the aegis of the World Health Organization, accomplished the eradication of smallpox $[3,10]$.

Natural reservoir of MPXV is rodents. Human monkeypox resembles the clinical course of smallpox that was prevalent on the African continent and is recorded predominantly in Central and Western Africa $[11,12]$. Its mortality rate in several studied human monkeypox outbreaks in Central Africa reached $16 \%[3,11]$. The specific feature of human monkeypox clinical course, distinguishing it from smallpox, is lymphadenitides. Another difference between the human monkeypox and smallpox is in that the human-to-human transmission efficiency of MPXV is considerably lower as compared with VARV [3]. That is why this virus has not so far caused any expanded epidemics.

CPXV displays the widest host range among the orthopoxviruses. Generally, human cowpox is a benign disease manifesting itself by isolated local lesions [3]. Human cowpox is recorded in the majority of European countries. Rodents (the main natural reservoir) or home pets and cattle (bridging hosts) represent the main sources of human CPXV infection [13-15]. In immunocompromised persons cowpox virus can cause a generalized eruption $[16,17]$ with lethal outcome in some cases [18].

VACV, used for vaccinating humans against smallpox, can be transmitted to man accidentally by contact with a vaccinee. Last years the number of reported outbreaks of the human diseases caused by the zoonotic VACV-like viruses is increasing in several countries [19-21].

VARV infection is a rare example of a strict anthroponosis caused by a virus propagating and spreading only within human populations; it is highly pathogenic for humans, being well adapted to overcome the defense barriers of this particular host. MPXV, CPXV, and VACV are zoonotic viruses with a wide range of sensitive species; they are evolutionary adapted to propagate in different mammalian hosts. In humans, they cause relatively rare sporadic disease cases when the virus is transmitted from an affected animal to a human [3]. ECTV, similarly to VARV, has a very narrow host range, being highly pathogenic only for certain mouse strains [8].

It is believed that viruses during coevolution with the host organism had incorporated into their genomes the coding sequences of various cellular genes and modified them for adapting to provide for their viability and preservation in the biosphere $[22,23]$. Acquiring the knowledge about how viruses overcome numerous protective systems of mammals, which are represented by molecular factors and cells of the immune system, we will not only get a deeper understanding but also discover new patterns in organization and functioning of these most important mammalian organism responses directed against infectious agents.

\section{Suppression of Molecular Recognition of Viruses by Innate Immune Cells}

Innate immune cells express a large repertoire of germ lineencoded pattern recognition receptors (PRRs) that recognize microbial components. The receptors include toll-like receptors (TLRs), nod-like receptors (NLRs), RIG-1-like receptors (RLRs), and AIM2-like receptors (ALRs) [24]. These PRRs bind microbial ligands and initiate signaling cascades which result in the activation of transcription factors such as nuclear factor kappa $\mathrm{B}(\mathrm{NF}-\kappa \mathrm{B})$, interferon regulatory factors (IRFs), and activating protein-1 (AP-1) involved in the expression of inflammatory and type I interferon (IFN) genes [1].

In response to infection, cells constituting the mammalian innate immune system, such as macrophages and dendritic cells, produce proinflammatory cytokines. IL$1 \beta$ and IL-18 are synthesized as cytoplasmic precursors, which should be cleaved by a cysteine protease termed caspase- 1 to acquire the active form. Caspase-1, in turn, is also synthesized as an inactive precursor, which can be activated within a large cytosolic protein complex called inflammasome [25-27]. Inflammasomes act as intracellular sensors responsive to conserved microbial components similarly to the functioning of TLRs on the cell surface or in endosomes. Proteins of the TLR family possess an intracellular TIR domain, which responds to infection by triggering intracellular signal cascades that activate innate immune reactions.

It was revealed that orthopoxvirus genomes contain two genes of TIR-containing proteins: VACV A46 and A52 [2830]. These proteins have different functions and specifically inhibit intracellular signal cascades activating transcription factor NF- $\kappa \mathrm{B}$, critical for innate immunity. A46 interacts with the factors MyD88, TIRAP, TRAM, and TRIF, and A52 with IRAK2 and TRAF6. It should be noted that CPXV and some VACV strains encode both above proteins, while VARV and MPXV, which are most pathogenic for humans, do not produce A52 VACV isologs (Table 1).

The crystallographic structure of A52 has been solved showing that this one is homodimer with folding similarity to B-cell-lymphoma- (Bcl-) 2-like proteins whose members inhibit apoptosis or activation of proinflammatory transcription factors [31]. To date a set of Bcl-2-like orthopoxviral proteins was discovered and characterized [32, 33] (Table 1). While these proteins share structural similarity, their degree of amino acid similarity is low indicating that they diverged long ago and although they share an ability to manipulate innate immune signaling pathways, they differ in their targets (Table 1) and mechanisms of action [32].

The crystallographic structure of VACV protein N1 (see Table 1) identified a groove similar to those of cellular antiapoptotic $\mathrm{Bcl}-2$ proteins. $\mathrm{N} 1$ is therefore unusual in its dual ability to modulate both apoptosis and inflammatory signaling. N1 inhibits proapoptotic and proinflammatory signaling using independent surfaces of the protein [34]. Analyses of the other available three-dimensional structures of the orthopoxviral Bcl-2-like proteins have shown that 
TABLe 1: Orthopoxviral Bcl-2-like proteins.

\begin{tabular}{|c|c|c|c|c|c|c|c|c|}
\hline \multirow{2}{*}{ Protein function } & \multicolumn{2}{|c|}{ VACV-COP } & \multicolumn{2}{|c|}{ CPXV-GRI } & \multicolumn{2}{|c|}{ MPXV-ZAI } & \multicolumn{2}{|c|}{ VARV-IND } \\
\hline & ORF & Size, aa & ORF & Size, aa & ORF & Size, aa & ORF & Size, aa \\
\hline $\begin{array}{l}\text { Inhibition of NF- } \kappa \text { B and IRF3 activation by interacting } \\
\text { with MyD88, TIRAP and TRIF, and TRAM }\end{array}$ & $\mathrm{A} 46 \mathrm{R}$ & 214 & A49R & 240 & A47R & 240 & A52R & 240 \\
\hline $\begin{array}{l}\text { Inhibition of NF- } \kappa \text { B activation by interacting with } \\
\text { IRAK2 and TRAF6 }\end{array}$ & A52R & 190 & A55R & 190 & - & - & J6R & 71 \\
\hline $\begin{array}{l}\text { Inhibition of NF- } \kappa \text { B activation by interacting with IKK } \\
\text { complex }\end{array}$ & B15R & 149 & B13R & 149 & B13R & 149 & B14R & 149 \\
\hline $\begin{array}{l}\text { Inhibition of NF- } \kappa \text { B and IRF3 activation by interacting } \\
\text { with IKK complex and TBK1, apoptosis inhibitor }\end{array}$ & N1L & 117 & Q1L & 117 & P1L & 117 & P1L & 117 \\
\hline $\begin{array}{l}\text { Inhibition of NF- } \kappa \text { B and IRF3 activation by interacting } \\
\text { with IRAK2, TRAF6, and DDX3 }\end{array}$ & K7R & 149 & M6R & 149 & $\mathrm{C} 6 \mathrm{R}$ & 149 & C4R & 149 \\
\hline $\begin{array}{l}\text { Inhibition of IRF3 and IRF7 activation by interacting } \\
\text { with TANK, NAP1, and SINTBAD }\end{array}$ & $\mathrm{C} 6 \mathrm{~L}$ & 151 & C14L & 156 & D11L & 153 & D9L & 156 \\
\hline Unknown & $\mathrm{C} 1 \mathrm{~L}$ & 224 & C19L & 231 & D19L & 214 & D14L & 214 \\
\hline Unknown & C16L & 181 & D5L & 153 & - & - & D1L & 153 \\
\hline Unknown & $\mathrm{N} 2 \mathrm{~L}$ & 175 & Q2L & 175 & $\mathrm{P} 2 \mathrm{~L}$ & 177 & $\mathrm{P} 2 \mathrm{~L}$ & 177 \\
\hline
\end{tabular}

VARV-IND: VARV strain India,1967, MPXV-ZAI: MPXV strain Zaire-I-96, CPXV-GRI: CPXV strain GRI-90, VAC-COP: VACV strain Copenhagen. ORF: open reading frame; aa: protein size in number of amino acid residues.

VACV proteins A52, B15, and K7 do not contain BH3peptide-binding groove important for inhibition of apoptotic stimuli and these proteins inhibit only activation of proinflammatory transcription factors [31,32].

Based on the sequence/structure similarity, it was proposed that additional VACV proteins $\mathrm{N} 2, \mathrm{C} 1$, and C16/B22 (and their orthopoxviral isologs) might have a similar role in suppression of PRR-induced host immune response as other studied Bcl-2-like proteins (Table 1), by antagonizing at different levels with the TLR signaling pathways [32, 34].

Thus, orthopoxviruses have a multigenic system controlling their recognition by innate immune cells. The detected distinctions between the Bcl-2-like genes of VARV, MPXV, $\mathrm{CPXV}$, and VACV require further studies of the properties of the corresponding proteins.

\section{The Ubiquitin-Proteasome Pathway in Viral Infection}

It has been recently discovered that protein degradation is an especially important regulatory cell process $[35,36]$. In the majority of cases, proteins in eukaryotic cells are degraded via an ubiquitin-directed pathway. Ubiquitin (Ub) comprises 76 amino acid (aa) residues and is among the most evolutionarily conserved polypeptides; Ub is covalently attached to target proteins by a coordinated action of three enzyme classes [37].

The ubiquitin-activating enzyme (E1) cleaves ATP to form a thioester bond between the $\mathrm{Ub} \mathrm{C}$-end and the cysteine in the active site of this enzyme. Thus, activated $\mathrm{Ub}$ is then transferred to the ubiquitin-conjugating enzyme (E2), also forming a thioester bond. E2-Ub interacts with ubiquitin-protein ligase (E3), which concurrently binds the target protein, frequently named the substrate. E3 causes transfer of the Ub from E2-Ub complex to the substrate by formation of the covalent isopeptide bond between the $\mathrm{Ub}$ $\mathrm{C}$-end and the lysine residues in target protein (substrate). Attachment of a single $\mathrm{Ub}$ can change the function or localization of the protein in the cell. A tandem attachment of Ub molecules, producing a polyubiquitin chain, can also modify the function or cell localization of target protein or causes involvement of such protein in degradation by the cellular 26S proteasome leading to protein cleavage into short peptides and Ub release [35].

Ubiquitin is the first member of the ever increasing family of ubiquitin-like (Ubl) proteins, which are also involved in modification of various proteins and their functions. Such modification processes are frequently of transient character because of existence of Ub/Ubl-deconjugating enzymes (Ub/Ubl-specific proteases) along with Ub/Ubl-conjugating enzymes. It has been discovered that Ubl attachment to target protein can frequently enhance the interaction of this modified protein with other proteins or, on the contrary, block its interaction with the target [37].

The most numerous group of E3 ligases contains cullinRING ubiquitin ligases (CRLs), multisubunit complexes comprising cullin proteins [38], RING H2 finger proteins (designated Rbx1, Roc1, or Hrt1) [39], variable substraterecognition subunit (SRS), and, for the majority of CRLs, additional adaptor proteins uniting SRS with other CRL proteins [36].

Proteins of the cullin family are hydrophobic proteins playing the role of a backbone for assembly of the CRL complex $[36,38]$. The CRL containing cullin-1 (CUL1), named SCF complex, has been most intensively studied. This complex comprises four subunits-Skp1, CUL1, F-boxcontaining protein, and Rbx1 (Figure 1(a)). The N-end of CUL1 protein binds to the Skp1 adaptor, which, in turn, interacts with F-box-containing protein. The $\mathrm{C}$-terminal part 
of CUL1 binds to Rbx1 protein, whose function is in the interaction with E2-Ub. In turn, F-box-containing protein $[40,41]$ provides for the interaction with substrate protein, which is ubiquitinated by the complex (see Figure 1(a)).

The CUL3-containing CRL complexes contain Rbx1; however, they differ from the other studied CRL classes by the absence of adaptor proteins [42]. The BTB-domaincontaining protein, accomplishing interaction with substrate protein of the complex by another protein-protein binding domain [43], directly interacts with the N-terminal CUL3 region (see Figure 1(b)).

Thus, the information accumulated so far demonstrates that a tremendous diversity of CRL complexes can be formed in mammalian cells. This agrees with the modern understanding that the modification of proteins by ubiquitin or ubiquitin-like polypeptides is important for the fate and functioning of the majority of proteins in eukaryotic cell and can be involved in regulation of various biological processes [44-46].

Taking into account the importance of ubiquitin-ligase and ubiquitin-proteasome systems for the function of eukaryotic cells, the role of viruses in regulation of these processes has been intensively studied recently. Although the data on this topic are sparse, it has been already discovered that viruses of various families can influence the protein ubiquitination to overcome the cell defense mechanisms, including apoptosis, type I interferon response, and antigen presentation by the class I major histocompatibility complex $[45,47,48]$.

The developmental cycle of orthopoxviruses takes place in the cell cytoplasm. Orthopoxviruses replicate in the discrete cytoplasmic structures called virus factories or virosomes. These structures are encompassed by endoplasmic reticulum membranes, resembling cytoplasmic mininuclei [49].

Recent experiments with VACV have demonstrated that proteasome inhibitors interfere with formation of virus factories in the cytoplasm of permissive cells and, as a consequence, lead to a radical decrease in virus replication $[50,51]$. These results suggest that a normal development of orthopoxvirus infection requires a functioning ubiquitinproteasome system.

Since it has been discovered that ubiquitin constitutes at least 3\% of the total protein in VACV virions [52], this suggests that either the ubiquitin-ligase system is important for modification of virus proteins and assembly of virus particles or ubiquitin-modified proteins are packaged into virions for further involvement in the early infection stages in sensitive cells.

Metabolism of animal viruses depending on their specific features is directed to utilize the structures of the cell cytoplasmic or nuclear protein skeleton. In particular, it is assumed that the virus-specific cytopathic effect is determined not by cell damage meaningless from the virus standpoint but rather by a specific rearrangement of cytoskeleton elements that would create the conditions for virus reproduction $[53,54]$. The cytoskeleton proteins are encoded by a large set of various genes with a tissuespecific expression. This determines the difference between the compositions of protein "backbone" in different cell types, which influences the functions of these cells [55]. These differences can influence the parameter of virus replication in the host organism, such as tissue tropism. In addition, the protein composition of cytoskeleton in various mammalian species (or cell cultures) can influence the overall sensitivity to certain viruses and determine the socalled host range. It is known that individual orthopoxvirus species considerably differ in the range of animal species where they can reproduce [56].

3.1. Viral Ankyrin-F-Box Containing Proteins. It is known that viral infections activate the cell antiviral signaling and inflammatory responses. The nuclear factor NF- $\kappa \mathrm{B}$, which regulates transcription of the genes involved in development of the apoptosis, inflammation, immune response, and cell proliferation [57], plays an important role in these responses. Activation of NF- $\kappa \mathrm{B}$ is controlled by ankyrin (ANK) repeat containing proteins of the $\mathrm{I} \kappa \mathrm{B}$ family, which interact with this factor. In an inactive form, NF- $\kappa \mathrm{B}$ (the dimer p65/p50) is bound to the inhibitory protein $\mathrm{I} \kappa \mathrm{B} \alpha$ which via six ANK repeats interacts with p65 subunit. In response to molecular signals of infection, $\mathrm{I} \kappa \mathrm{B} \alpha$ kinase (IKK) is phosphorylated by cellular protein kinase to phosphorylate $\mathrm{I} \kappa \mathrm{B} \alpha$ at the serine residues at positions 32 and 36. The phosphorylated $\mathrm{I} \kappa \mathrm{B} \alpha$ is polyubiquinated by the SCF complex at lysine 48 and degraded by the $26 \mathrm{~S}$ proteasome complex, thereby removing the NF- $\kappa \mathrm{B}$ inhibition; this factor moves to the cell nucleus and stimulates gene transcription via the interaction with specific DNA sequences $[57,58]$.

Different VACV strains inhibit activation of the cellular transcription factor $\mathrm{NF}-\kappa \mathrm{B}$, thereby providing inhibition of inflammatory response development, which is among the first reactions of nonspecific protection from infectious agents. It was demonstrated that the highly attenuated VACV strain MVA failed to inhibit NF- $\kappa$ B activation. Recombination-based introduction of the $K 1 L$ gene from VACV strain WR to the MVA genome restored the ability of the virus to inhibit the activation of cellular factor NF$\kappa \mathrm{B}[59]$. VACV protein $\mathrm{K} 1$ belongs to the family of ANK proteins [60-62] and it was assumed that $\mathrm{K} 1$ can inhibit degradation of the cellular $\mathrm{I} \kappa \mathrm{B} \alpha$ via competing with it for phosphorylation by the enzyme IKK and subsequent ubiquitination and degradation. Another ANK-containing protein, CPXV C9 (not synthesized by VACV; Table 1) is likely to act in an analogous manner [58] and, consequently, is able to rescue the mutation VACV K1L ${ }^{-}[63]$.

Our analysis has demonstrated [62-64] that orthopoxviruses code for a large set of ANK proteins (Table 2). This is the largest family of orthopoxvirus proteins; moreover, each species has its specific set of the corresponding genes [63]. Of the natural orthopoxviruses, CPXV, displaying the widest host range, has 14 unique ANK genes in its genome (two of them are duplicated in the terminal genomic regions); MPXV, eight such genes and VARV, a stringently anthroponotic virus, five ANK genes, VACV-COP encodes five ANK proteins (three match the VARV proteins), while the highly attenuated variant VACV-MVA, obtained by multiple passages on chorioallantoic membranes (CAMs) of 


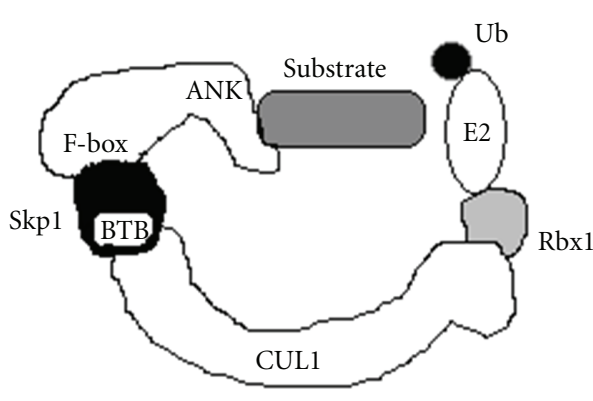

(a)

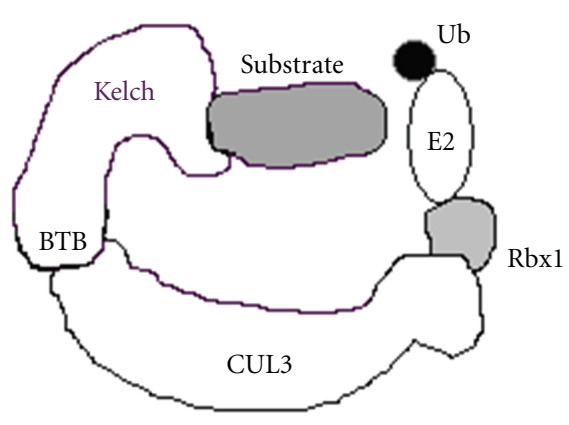

(b)

FIgURE 1: A schematic of two classes of orthopoxvirus E3 ubiquitin ligases: (a) SCF E3 ligase and (b) BTB-kelch/Cul3 E3 ligase.

chick embryos and having a very narrow range of sensitive cell cultures, retained only one ANK gene [65].

It has been shown that many poxvirus ANK proteins contain F-box sequences at their C-ends [66]. Such combination of domains is characteristic of poxviruses only. In the cellular proteins, F-box domain is usually localized to the N-terminal part. In addition, the combination of ANK and F-box domains has not been found in cellular proteins $[67,68]$. Our analysis allowed to detect F-box sequences in the C-terminal regions in 13 of the 14 CPXV ANK proteins (Table 1) [63].

Recently, it has been experimentally demonstrated for the ANK-F-box proteins C9 (CHOhr) of CPXV [58], G1 of VARV (D3/H3 in CPXV) [69], 186R of VACV-MVA (B16 in CPXV) [70], as well as EVM002, EVM005, and EVM154 of ECTV (D3/H3, D8, and B3 in CPXV) [71] that they interact with the cellular SCF complex (Figure 1(a)) and, presumably, provide for specific interaction with substrate proteins of cellular or viral origins, which are then ubiquitinated by this complex. An important problem is to detect these substrate proteins for each of the numerous orthopoxvirus proteins of the considered family.

3.2. Viral BTB-Kelch-Like Proteins. Among all the viruses, only the representatives of the family Poxviridae contain the genes of kelch-like proteins in their genomes. According to structural similarity, they are ascribed to the same group as Drosophila kelch protein (BTB-kelch) [72-74]. These proteins contain the N-terminal BTB domain and Cterminal kelch domain. Computer analysis of orthopoxvirus genomes has demonstrated that CPXV codes for six BTBkelch family proteins with a size of about 500 AA residues each and mutual identity in AA sequence in the range of 22$26 \%$. VACV genome codes for only three full-sized kelch-like proteins, which are highly homologous to the corresponding CPXV proteins; as for the highly attenuated strain VACVMVA, unable to replicate in the majority of mammalian cell lines, it retained only one gene of this family [65]. The same gene is the only gene in MPXV genome encoding a BTBkelch protein. As for VARV genome, all genes of this family are destroyed due to multiple mutations; consequently, only short potential ORFs, which are nonfunctional fragments of the genes of a precursor virus, are detectable in this virus
[74] (Table 3). ECTV codes for four genes of the considered family-EVM18, EVM27, EVM150, and EVM167, which correspond to the CPXV-GRI genes C18L, G3L, A57R, and B19R $[23,75]$.

The absence of the genes from this family in various VARV isolates and the possibility of their deleting in VACV without any loss in its viability in cell culture [76] indicate that these genes are not vitally important for orthopoxvirus replication in cultured cells. Presumably, these genes are important for manifestation of species-specific properties of orthopoxviruses in vivo. It has been assumed that these genes can play a role in adaptation, that is, they can determine the host range (tissue tropism) and/or the possibility of virus persistence in animal body [23]. In particular, CPXV, low pathogenic for humans and displaying the widest range of sensitive animals in nature, codes for the largest set of BTBkelch proteins. In VARV, highly pathogenic for its only host, human, in organism of which this virus cannot persist, all the genes of BTB-kelch subfamily are mutationally destroyed $[63,64]$.

The available data suggest that various BTB-kelch proteins interact with CUL3 (Figure 1(b)) rather than with the other cullins, that is, BTB-kelch proteins are substratespecific adaptors for CUL3 ubiquitin-ligase complex and regulate modification and/or degradation of various proteins [42].

When studying the properties of orthopoxvirus BTBkelch proteins, it has been found that the ECTV proteins EVM150 and EVM167 are involved in formation of active CUL3-containing ubiquitin ligases [77]. Two other proteins, EVM18 and EVM27, also interact with CUL3 [78]. Since the mutual homology of these viral proteins is low, it is likely that their functions are different and they interact with different targets. It has been experimentally demonstrated that a directed deletion of individual genes encoding EVM18, EVM27, or EVM167 radically decreases the ECTV virulence for white mice, while the damage of EVM150 gene has no effect on the virulence [79].

Deletion of four CPXV BTB-kelch genes led to a decrease in the cytopathic effect on cell culture and statistically significant reduction in formation of the virus-induced cytoplasmic pseudopodia $[80,81]$. 
TABLE 2: Orthopoxviral ankyrin-F-box-like proteins.

\begin{tabular}{|c|c|c|c|c|c|c|c|}
\hline \multicolumn{2}{|c|}{ VACV-COP } & \multicolumn{2}{|c|}{ CPXV-GRI } & \multicolumn{2}{|c|}{ MPXV-ZAI } & \multicolumn{2}{|c|}{ VARV-IND } \\
\hline ORF & Size, aa & ORF & Size, aa & ORF & Size, aa & ORF & Size, aa \\
\hline C19L* & 259 & $D 3 L^{*}$ & 586 & $\mathrm{~J}^{3} \mathrm{~L}^{*}$ & 587 & None & None \\
\hline C17L* & 386 & D4L L $^{*}$ & 672 & None & None & None & None \\
\hline None & None & $D 8 L$ & 661 & None & None & None & None \\
\hline None & None & D14L & 764 & None & None & None & None \\
\hline None & None & C1L & 437 & D1L $L^{*}$ & 437 & None & None \\
\hline None & None & C3L & 833 & None & None & None & None \\
\hline None & None & $C 9 L$ & 668 & D7L & 660 & D6L & 452 \\
\hline C9L & 634 & C11L & 614 & D9L & 630 & D7L & 153 \\
\hline M1L & 472 & O1L & 474 & O1L & 442 & O1L & 446 \\
\hline $\mathrm{K} 1 \mathrm{~L}$ & 284 & M1L & 284 & $\mathrm{C} 1 \mathrm{~L}$ & 284 & $\mathrm{C} 1 \mathrm{~L}$ & 66 \\
\hline B4R & 558 & $B 3 R$ & 558 & B5R & 561 & B6R & 558 \\
\hline B18R & 574 & $B 16 R$ & 574 & None & None & B19R & 574 \\
\hline B20R & 127 & B18R & 795 & B17R & 793 & B21R & 787 \\
\hline B21R* & 91 & K1R & 581 & None & None & None & None \\
\hline None & None & None & None & N4R* & 437 & None & None \\
\hline B23R* & 386 & H2R* & 672 & None & None & None & None \\
\hline B25R* & 259 & $H 3 R^{*}$ & 586 & $\mathrm{~J}_{1} \mathrm{R}^{*}$ & 587 & G1R & 585 \\
\hline
\end{tabular}

Asterisks denote ORFs that are duplicated in left and right inverted terminal repeat regions of the viral genome. ORFs with full length are set in bold. The ORFs for the proteins with experimentally confirmed interaction with the cellular Cullin1-containing ubiquitin-protein ligase are indicated by bold italic letters.

TABLE 3: Orthopoxviral BTB-kelch-like proteins.

\begin{tabular}{lccccccc}
\hline \multicolumn{2}{c}{ VACV-COP } & \multicolumn{2}{c}{ CPXV-GRI } & \multicolumn{2}{c}{ MPXV-ZAI } & \multicolumn{2}{c}{ VARV-IND } \\
ORF & Size, aa & ORF & Size, aa & ORF & Size, aa & ORF & Size, aa \\
\hline None & None & D11L & $\mathbf{5 2 1}$ & None & None & None & None \\
C2L & $\mathbf{5 1 2}$ & C18L & $\mathbf{5 1 2}$ & D18L & 107 & None & None \\
F3L & $\mathbf{4 8 0}$ & G3L & $\mathbf{4 8 5}$ & C9L & $\mathbf{4 8 7}$ & C7L & 179 \\
A55R & $\mathbf{5 6 4}$ & A57R & $\mathbf{5 6 4}$ & None & None & J7R & 71 \\
B10R & 166 & B9R & $\mathbf{5 0 1}$ & None & None & None & None \\
None & None & B19R & $\mathbf{5 5 7}$ & B18R & 70 & B22R & 70 \\
\hline
\end{tabular}

ORFs with full length are set in bold. The ORFs for the proteins with experimentally confirmed interaction with the cellular Cullin 3-containing ubiquitinprotein ligase are indicated by bold italic letters.

Deletion of individual kelch-like genes in the VACV genome provided for demonstrating that the damage of genes C2L or A55R (see Table 2) led to similar effects, appearing as changes in the morphology of virus plaques on cell culture monolayer, decrease in virus-induced cytoplasmic pseudopodia, decrease in $\mathrm{Ca}^{2+}$-independent adhesion of VACVinfected cells, and induction of larger lesions in the model of intradermal infection of mouse ear pinnae as compared with the wildtype virus $[82,83]$. Damage of the VACV kelch-like gene F3L did not cause so pronounced effects [84]. Interestingly, this particular single BTB-kelch gene remained in MPXV (see Table 3) and the highly attenuated VACV strain MVA.

The ability of orthopoxvirus BTB-kelch-like proteins to interact with Cullin-3-containing ubiquitin-protein ligase to a considerable degree relates this family to the family of orthopoxvirus ankyrin-F-box-like proteins interacting with Cullin-1-containing ubiquitin-protein ligase. Most likely, the proteins of these two families are involved in organization of the multifactorial intricate system of interactions of virus proteins with one another and cellular components. We believe that such interactions can determine a wide range of animal tissues and species sensitive to CPXV as well as for the tolerant mode of relationships between this virus and the host. One can speculate that destruction of the majority of the genes/proteins belonging to these two families, characteristic of VARV, is the most likely reason underlying a drastic narrowing of the VARV host range and its transition to an "aggressor" mode [63]. Note that VARV retained five genes encoding ankyrin-F-box proteins (Table 2), whereas the genes for BTB-kelch proteins are completely destroyed (Table 3). 


\section{Viral Apoptosis Inhibitors}

One of the first lines of the organism's nonspecific defense against infectious agents and probably one of the most ancient ones is apoptosis (programmed cell death) [85, 86]. After a cell has been infected by a virus, apoptosis serves to kill the cell, thus preventing virus proliferation and protecting nearby cells from the infection. Apoptosis is a very common phenomenon in multicellular organisms. It is primarily mediated by cysteine proteases termed caspases. An important role in apoptosis regulation belongs to mitochondria and $\mathrm{Bcl}-2$ proteins. Interferon-induced synthesis of RNase L (see Section 5) causes apoptosis mediated by caspases 8,9 , and 2 [87].

A key function in the induction of programmed cell death is performed by cellular caspase 1 , which specifically cleaves inactive prointerleukin- $1 \beta$ and producing the mature interleukin- $1 \beta$ form (IL- $1 \beta$ ). It should be noted that IL- $1 \beta$ itself is not associated with apoptosis; that is, it is other proteins that caspase- 1 targets when triggering programmed cell death [88]. It was revealed that the product of the CPXV gene SPI-2 is an inhibitor of caspases 1 and 8 and, therefore, an apoptosis inhibitor $[89,90]$. A comparison of SPI-2 amino acid sequences showed that CPXV and VACV proteins are very similar but differ significantly from the VARV isolog [3].

Based on an in silico amino acid sequence analysis, another VACV protein, C12 (in VARV-IND, B25; see Table 4), was also classified into the same family of protease inhibitors as SPI-2 and named SPI-1; it was shown to act as an apoptosis inhibitor, too. However, the principle of its action so far remains unclear. Supposedly, SPI-1 inhibits a caspaseindependent apoptosis pathway [91].

VACV protein F1 is localized in mitochondria and acts as a caspase 9 inhibitor, suppressing the programmed death of infected cells [92-94]. The amino acid sequence of another conserved orthopoxvirus protein, N1 (VACV-COP, Table 4), has little homology to the Bcl-2 sequence, but its tertiary structure closely resembles the proteins of this family, and N1 is an apoptosis inhibitor (see additionally Section 2) [34, 95].

Some VACV strains, as well as the camelpox virus, contain a gene of a transmembrane protein of 237 amino acids located in the Golgi apparatus, which suppresses apoptosis of infected cells [96]. CPXV encodes a somewhat shorter version of the same protein (T1), while VARV and MPXV lack gene of the isolog protein (Table 4).

Double-stranded RNA apparently also can induce apoptosis, as suggested by investigation of a VACV strain carrying a mutant $E 3 L$ variant. It was shown that disruption of this gene results not only in increased interferon sensitivity of the virus (see Section 5) but also in activation of apoptosis of infected cells [97]. This gene is fairly well conserved among different orthopoxvirus species.

The first orthopoxvirus ubiquitin ligase belonging to the family of mono-subunit RING-containing E3 ligases was found in ECTV. First, it was shown that the RING domaincontaining ECTV protein $\mathrm{p} 28$ is a virulence factor inhibiting TNF-induced apoptosis [98]. This viral protein localized in cytoplasmic virus factories is essential for virus replication in macrophages [99]. Under consideration of the growing body of knowledge concerning RING domain-containing ubiquitin ligases, investigation of ECTV and VARV p28 proteins showed that p28 acts as an ubiquitin ligase [100]. The respective gene is highly conserved among VARV, MPXV, CPXV, and ECTV, but inactivated in the known VACV strains. The molecular target (viral or cellular protein) of orthopoxvirus ubiquitin ligase p28 has not been identified yet.

Thus, orthopoxviruses possess at least seven genes encoding apoptosis inhibitors with very diverse modes of action (Table 4). This observation further confirms the importance of apoptosis in the mammalian system of antiviral defense.

\section{Viral Interferon Inhibitors}

Mammalian cells respond to viral infection by producing interferons (IFNs). The initial production of type I IFNs is due to activation of IFN regulatory factors (IRFs), and in particular IRF3, downstream of PRRs, which recognize viral DNA, RNA, and proteins [33]. It was discovered that some orthopoxviral Bcl-2-like proteins inhibit PRR-induced activation of IRFs (see Section 2 and Table 1) and therefore suppress IFN production.

IFNs are produced and secreted by animal cells also in response to double-stranded RNA molecules (dsRNA) synthesized in the course of viral infection. IFNs bind to specific cell receptors and induce antiviral defense state [101]. IFN-induced antiviral cell state is determined by at least two enzymatic pathways. One of them involves IFNinduced dsRNA-activated protein kinase (PKR); another one depends on $2-5 \mathrm{~A}\left[\mathrm{ppp}\left(\mathrm{A2} 2^{\prime} \mathrm{p}\right) \mathrm{nA}\right]$ synthetase (usually termed 2-5A synthetase). The protein kinase is activated by autophosphorylation, which occurs after protein binding to dsRNA. The activated PKR phosphorylates subunit alpha of the eukaryotic translation initiation factor (eIF-2 $\alpha$ ), thus blocking protein synthesis. The other enzyme, 2-5A synthetase is activated by dsRNA and catalyzes ATP polymerization to $2^{\prime}-5^{\prime}$ oligoadenylates, which, in turn, activate latent cellular endo-RNase L. RNase L cleaves mRNA and rRNA molecules, thus also disturbing protein synthesis.

Although orthopoxviruses produce high levels of virusspecific dsRNA in the late phase of their life cycle [102], they are highly resistant to IFN action [103]. VACV gene E3L encodes an inhibitor of the IFN-induced PRK [104]. This viral protein produced directly after cell infection can bind to dsRNA, competing with the specific cellular protein kinase and preventing the enzyme activation. Another VACV gene, $K 3 L$, encodes an eIF- $2 \alpha$ homologue competing with endogenous eIF- $2 \alpha$ for phosphorylation by activated PRK [105]. A mutant VACV strain with disrupted $K 3 L$ is interferonsensitive and produces two orders of magnitude less viral progeny [106]. Thus, orthopoxviruses produce proteins that inhibit the activity of the IFN-induced PRK in two independent ways.

It should be noted that although the sequences of viral eIF- $2 \alpha$ homologues are well conserved within species, the VARV protein has numerous differences in amino acids from highly homologous VACV and CPXV isologs, while MPXV 
TABLE 4: Orthopoxviral proteins modulating defense reactions of mammals.

\begin{tabular}{|c|c|c|c|c|c|c|c|c|}
\hline \multirow{2}{*}{ Protein function } & \multicolumn{2}{|c|}{ VACV-COP } & \multicolumn{2}{|c|}{ CPXV-GRI } & \multicolumn{2}{|c|}{ MPXV-ZAI } & \multicolumn{2}{|c|}{ VARV-IND } \\
\hline & ORF & Size, aa & ORF & Size, aa & ORF & Size, aa & ORF & Size, aa \\
\hline $\begin{array}{l}\text { Apoptosis inhibitor, caspase- } 1 \text { and caspase- } 8 \\
\text { inhibitor, SPI-2 }\end{array}$ & B13R & 116 & $\mathrm{~B} 12 \mathrm{R}$ & 345 & $\mathrm{~B} 12 \mathrm{R}$ & 344 & $\mathrm{~B} 13 \mathrm{R}$ & 344 \\
\hline Apoptosis inhibitor, SPI-1 & $\mathrm{C} 12 \mathrm{~L}$ & 353 & B20R & 375 & $\mathrm{~B} 19 \mathrm{R}$ & 357 & $\mathrm{~B} 25 \mathrm{R}$ & 372 \\
\hline Apoptosis inhibitor, Bcl-2-like & N1L & 117 & Q1L & 117 & P1L & 117 & P1L & 117 \\
\hline $\begin{array}{l}\text { Mitochondria-associated apoptosis inhibitor, } \\
\text { caspase- } 9 \text { inhibitor }\end{array}$ & F1L & 226 & G1L & 238 & $\mathrm{C} 7 \mathrm{~L}$ & 219 & C5L & 251 \\
\hline $\begin{array}{l}\text { Apoptosis inhibitor, transmembrane protein of } \\
\text { Golgi apparatus }\end{array}$ & None & None & $\mathrm{T} 1 \mathrm{R}$ & 210 & R1R & 105 & None & None \\
\hline $\begin{array}{l}\text { Apoptosis inhibitor, RING-domain containing E3 } \\
\text { ubiquitin ligase }\end{array}$ & None & None & C7R & 242 & D5R & 242 & $\mathrm{D} 4 \mathrm{R}$ & 242 \\
\hline $\begin{array}{l}\text { Apoptosis inhibitor, dsRNA-binding, interferon } \\
\text { resistance }\end{array}$ & E3L & 190 & $\mathrm{~F} 3 \mathrm{~L}$ & 190 & F3L & 153 & E3L & 190 \\
\hline eIF- $2 \alpha$ homolog, interferon resistance & $\mathrm{K} 3 \mathrm{~L}$ & 88 & M3L & 88 & None & None & $\mathrm{C} 3 \mathrm{~L}$ & 88 \\
\hline Phosphatase, dephosphorylation of Stat 1 & $\mathrm{H} 1 \mathrm{~L}$ & 171 & $\mathrm{~J} 1 \mathrm{~L}$ & 171 & H1L & 171 & $\mathrm{I} 1 \mathrm{~L}$ & 171 \\
\hline$\gamma$-IFN-binding & $\mathrm{B} 8 \mathrm{R}$ & 272 & B7R & 271 & B9R & 267 & B9R & 266 \\
\hline$\alpha / \beta$-IFN-binding & B19R & 353 & $\mathrm{~B} 17 \mathrm{R}$ & 351 & $\mathrm{~B} 16 \mathrm{R}$ & 352 & B20R & 354 \\
\hline IL- $1 \beta$-binding & None & None & $\mathrm{C} 8 \mathrm{~L}$ & 124 & D6L & 126 & D5L & 126 \\
\hline IL-18-binding & B16R & 290 & $\mathrm{~B} 14 \mathrm{R}$ & 326 & B14R & 326 & B15R & 63 \\
\hline Complement binding & $\mathrm{C} 3 \mathrm{~L}$ & 263 & $\mathrm{C} 17 \mathrm{~L}$ & 259 & D14L & 216 & D12L & 263 \\
\hline TNF- and chemokine-binding, CrmB & B28R & 122 & H4R & 351 & $\mathrm{~J} 2 \mathrm{R}$ & 348 & G2R & 349 \\
\hline TNF-binding, CrmC & A53R & 103 & A56R & 186 & None & None & None & None \\
\hline TNF- and chemokine-binding, CrmD & None & None & $\mathrm{K} 2 \mathrm{R}$ & 322 & None & None & None & None \\
\hline TNF-binding, CrmE & None & None & K3R & 167 & K1R & 70 & None & None \\
\hline CC-chemokine-binding & B29R & 244 & I5R & 255 & $\mathrm{~J} 3 \mathrm{R}$ & 246 & G3R & 253 \\
\hline CС- и СXC-chemokine-binding & A41L & 219 & $\mathrm{~A} 43 \mathrm{~L}$ & 219 & A41L & 221 & $\mathrm{~A} 46 \mathrm{~L}$ & 218 \\
\hline $\begin{array}{l}\text { Inhibitor of NK-mediated NKG2D-dependent lysis } \\
\text { of infected cells }\end{array}$ & None & None & C2L & 178 & N3R & 176 & None & None \\
\hline Inhibitor of MHC class II antigen presentation & A35R & 176 & A36R & 176 & A37R & 176 & A38R & 60 \\
\hline $\begin{array}{l}\text { Inhibitor of MHC class I complexes release from the } \\
\text { PLC }\end{array}$ & None & None & D10L & 96 & None & None & None & None \\
\hline $\begin{array}{l}\text { Inhibitor of the intracellular trafficking of MHC } \\
\text { class I molecules }\end{array}$ & B9R & 77 & B8R & 221 & B10R & 221 & None & None \\
\hline
\end{tabular}

ORFs that are altered/nonfunctional as compared with a CPXV-GRI counterpart are set in bold.

does not encode this interferon resistance factor due to multiple mutations of the respective gene (Table 4).

In the course of VACV infection, E3L is expressed from the first and the second initiator codon producing the long and the short protein forms, respectively [106]. The $\mathrm{N}$-terminal domain of the long form is required for the protein binding to Z-form DNA, which explains its nuclear localization and its pathogenic properties $[107,108]$. The Cterminal domain of both the long and the short form binds dsRNA and inhibits the activation of the PRK [109] and 25A synthetase [110]. In MPXV-ZAI, the first initiator triplet is disrupted by a mutation; for this reason, only the short protein form is translated. Thus, MPXV differs from other orthopoxvirus species in the unique organization of viral intracellular interferon resistance factors [64, 111], which apparently results in decreased propagation rates in vivo and, consequently, decreased efficiency of airborne transmission of the virus, which is indeed the case for human monkeypox, as compared to smallpox.

Recently, it has been demonstrated that VACV E3 protein also inhibits the type III $\lambda$-IFN-mediated antiviral response [112].

Blocking the function of Stat (signal transducer and activator of transcription) proteins, which are critical for antiviral responses, has evolved as a common mechanism for pathogen immune evasion. The VACV-encoded phosphatase $\mathrm{H} 1$ is critical for virus replication and plays an additional role in the evasion of host defense by dephosphorylating Stat1 and blocking IFN-stimulated innate immune responses. It was demonstrated that VARV $\mathrm{H} 1$ isolog (I1 for VARVIND, see Table 4) is more active than VACV H1 in Stat1 dephosphorylation [113].

A unique and efficient IFN evasion strategy employed additionally by poxviruses is to encode soluble proteins that 
are secreted from infected cells and function as soluble IFN decoy receptors. These factors providing interferon resistance in orthopoxviruses are extracellular $\gamma$-IFN-binding protein [114] and type I $\alpha / \beta$-IFN-binding protein $(\alpha / \beta$-IFN-BP) [115]. Earlier we have revealed pronounced species-specific differences in amino acid sequences of $\alpha / \beta$-IFN-BPs of orthopoxviruses $[3,116]$. Recently it has been shown that the VARV $\alpha / \beta$-IFN-BP binds the human ligands with higher affinity than the VACV $\alpha / \beta$-IFN-BP [117].

Thus, orthopoxviruses possess a multigene system providing a high level of interferon resistance. Differences found among these genes/proteins in VARV, MPXV, CPXV, and VACV (Table 4) call for further investigation of their properties.

\section{Viral Inhibitors of Inflammatory Response}

Inflammatory reactions play an important role in the early nonspecific protection of the organism against the viral infection. They are induced rapidly to limit the virus dissemination during the first hours and days upon infection while the full-fledged adaptive immune response is being formed. It is known that the complement system and the cytokines, such as tumor necrosis factor (TNF), interleukin$1 \beta$ (IL-1 $\beta)$, gamma-interferon ( $\gamma$-IFN), and chemokines, play the key role in inducing the inflammatory reactions [118]. In addition, several other mediators influence either directly or indirectly the development of the inflammatory process [116, 119-121]. Therefore, poxviruses potentially need several genes whose protein products are able to act as inhibitors of various stages of inflammation development to suppress efficiently the inflammatory response.

The first viral gene whose product represses inflammatory response to infection was found in CPXV and termed SPI-2 (B12R for CPXV-GRI, see Table 4) [122]. As noted above (see Section 3), SPI-2 inhibits caspase 1 activity and thus prevents the processing of pro-IL- $1 \beta$ to IL- $1 \beta$ and its secretion from the infected cell, suppressing, as a result, the induction of local inflammatory reactions. In addition, SPI-2 inhibits the production of inflammatory mediators (leukotrienes) in the arachidonic acid metabolism [123]. Furthermore, as discussed above, SPI-2 is also involved in suppressing apoptosis of the infected cell. Thus, this protein evidently plays an important role in determining orthopoxvirus pathogenicity in vivo. It should be noted that amino acid sequences of SPI-2 variants present in VARV, MPXV, and CPXV are somewhat different [32]. In the case of VACV-COP, the gene encoding this protein is damaged (Table 4).

It was shown experimentally that the VACV-WR gene $B 15 R$ encodes a secreted glycoprotein acting as a soluble IL$1 \beta$ receptor [124]. The production of this soluble receptor prevents the development of systemic reactions (such as fever) in VACV-infected mice [125]. It was shown that a VACV-WR strain with disrupted B15R had increased virulence in mice (when administered intranasally) [124]. A further analysis showed that VACV strains associated with a higher frequency of postvaccination complications in humans lack IL-1 $\beta$-binding activity [125]. These data agree well with the fact that the respective gene in VARV is disrupted (by fragmentation) (Table 4).

Thus, we may hypothesize that VARV suppresses production and secretion of IL-1 $\beta$ by infected cells but does not inhibit the effect of extracellular IL- $1 \beta$ synthesized by other cells of the body. This suggests that VARV is capable of suppressing local inflammatory reactions due to SPI2 production in the region of virus replication; however, it does not inhibit the systemic reactions, as it is unable to synthesize IL-1 $\beta$-binding protein. Decrease in the local inflammatory reactions may assist a more active virus replication, while uncontrolled development of the systemic reactions weakens the overall resistance of the organism to infection. A concurrent development of these reactions is likely to boost the pathogenic effect of the viral infection on the host organism. In the case of MPXV and CPXV, both genes in question are native (Table 4).

Orthopoxviruses, in particular, VACV-WR, but not the less virulent VACV-COP strain, also encode an IL-18-binding protein (Table 4), which is secreted from the cell and suppresses the activity of proinflammatory IL-18 [126].

Similarly to other cytokines, TNF performs multiple functions [118]. In particular, as noted above, it is a key cytokine inducing inflammation in the infected host along with IL- $1 \beta$ and IL-18. It was shown that VARVIND gene G2R encodes CrmB protein homologous to type II TNF receptor [127]. An orthologous TNF-inhibitory protein called M-T2 is an important secreted virulence factor of the rabbit myxoma virus (a poxvirus of the genus Leporipoxvirus). Its VARV analogue G2 apparently has similar properties. An important difference between VARV and VACV is that the latter possesses no genes encoding TNF receptor analogues. In the CPXV genome, we detected five genes of the TNF receptor family [23]. Four of them have TNF-binding activity [128-131] (Table 4).

An analysis of amino acid sequences of $\mathrm{CrmB}$ isologs detected numerous species-specific differences. Using a baculuvirus expression system, we obtained individual $\mathrm{CrmB}$ proteins of VARV, MPXV, and CPXV and showed that their ability to suppress the activity of human, mouse, and rabbit TNFs differs considerably. Only CrmB-VARV inhibits human TNF activity with high efficiency $[132,133]$. Presumably, this is a result of evolutionary adaptation of the viral receptors to the ligands of their hosts.

It was recently shown that orthopoxvirus TNF-binding protein $\mathrm{CrmB}$ possesses a further biological activity; that is, it has high affinity to certain chemokines critically involved in attracting dendritic cells, B-, and T-lymphocytes to the inflammation focus [134]. Its immunomodulatory activity is determined by the unique C-terminal domain termed SECRET (smallpox virus-encoded chemokine receptor). The amino acid sequence of this domain has no homology to any vertebrate protein or to any other known viral chemokinebinding protein. De novo modeling of the spatial structure of the SECRET domain showed that it might be a structural homologue of the secreted CC-chemokine-binding protein G3 of VARV (Table 4), in spite of the low similarity of their amino acid sequences [135]. 
Chemokines are chemoattractant cytokines, which control migration and effector functions of leukocytes, thereby playing an important role in development of inflammatory response and protection against pathogens [136]. It was demonstrated that VACV strain Lister at the early stages of infection produced a protein secreted from the cells in large amounts [137], which bound a wide range of CC chemokines and inhibited their activities [138]. This gene is damaged in many other VACV strains. Presumably, isologs of this protein (G3 in VARV-IND) of various orthopoxvirus species have different functions, as analysis of their amino acid sequences detected considerable species-specific distinctions [3].

The VACV protein A41 and its orthopoxvirus isologs also are secreted glycoproteins that efficiently and selectively bind to certain CC and CXC chemokines preventing chemokine-induced leukocyte migration to the infection locus $[139,140]$. This chemokine-binding protein probably is essential for virus propagation, since it is conserved in all orthopoxvirus species studied (Table 4).

Interestingly, all orthopoxviruses in question also produce a soluble $\gamma$-IFN-receptor, which can modulate the host's inflammatory response to infection [141-143]. The protein B9 of VARV-IND and its isolog produced by VACV-COP contain a considerable number of amino acid substitutions [144]. Probably, these species-specific differences in the structure of viral $\gamma$-IFN-binding protein are related to the difference in VARV and VACV virulence.

In addition to the above genes, orthopoxviruses also carry a gene of a complement-binding protein $(C 3 L$ in VACV-COP) [145], one of whose functions may be regulation of inflammation. The complement system comprises over 20 blood plasma proteins. Antiviral functions of the complement systems include virus neutralization, lysis of infected cells, and enhancement of inflammatory and adaptive immune response [2, 119].

The VACV protein C3, named VCP, secreted from infected cells and controlling the reaction of complement activation comprises four short degenerated repeats of approximately 60 amino acids each (short consensus repeat, SCR) characteristic of the protein family of complement activation regulators (RCA) [146]. It is considered that the gene encoding VCP originated initially due to incorporating a part or the complete coding sequence of a protein belonging to RCA family of the host into the viral genome followed by adaptation (alteration) of the gene in question to perform the functions necessary for the virus [147]. The X-ray structural analysis showed that SCR sequences of VCP form a series of discrete tightly linked compact domains [148].

VCP is a unique multifunctional viral protein functionally resembling as different RCA proteins as factor $\mathrm{H}$, membrane-bound cofactor protein, type I complement receptor, and decay-accelerating factor (DAF). Firstly, VCP binds complement components $\mathrm{C} 3 \mathrm{~b}$ and $\mathrm{C} 4 \mathrm{~b}$; secondly, it blocks different stages of the complement cascade and inhibits both the classical and the alternative complement pathways; thirdly, it blocks complement-driven virus neutralization activated by antiviral antibodies, and, finally, binds heparin-like molecules on the surface of endothelial cells, blocking the binding of chemokines and preventing signal transduction for chemotaxis [119]. The model of CPXVinfected mice showed that VCP suppresses inflammatory response in vivo $[149,150]$.

VCPs of VARV, CPXV, and VACV contain four SCRs each. We have revealed the unique structure of the MPXV VCP $[3,151]$. Due to premature termination of synthesis, the protein sequence is truncated and the C-terminal SCR-4 is deleted in Central African MPXV strains, whereas Western African MPXV strains lack the gene for VCP completely [3]. Possibly this deletion or truncation of the gene for VCP prevents effective inhibition of inflammatory response by MPXV and therefore the specific feature of human monkeypox clinical course, distinguishing it from smallpox, is lymphadenitides.

Amino acid sequences of VACV and VARV VCPs differ at 12 positions. A baculovirus system was used to produce individual VCPs of VARV and VACV [152]. It was shown that VCP of VARV is a significantly more efficient inhibitor of human complement than its VACV counterpart. This observation further supports the concept that viral soluble receptors are evolutionary adapted to the host's ligands.

To sum up, orthopoxviruses possess a multigene system controlling at different stages development of the host's inflammatory reactions. Orthopoxviruses display speciesspecific distinctions not only in the set of these genes but also in their structure, and as a result in targeted activities of the encoding proteins.

\section{Orthopoxvirus Modulation of Cellular Immune Response}

One of the principal mechanisms of the innate cellular immunity involves nonspecific lysis of virus-infected cells by natural killer (NK) cells [153]. The latter are activated by soluble mediators or in a direct cell contact. NK proliferation peaks on days 2-3 of orthopoxvirus infection; however, these cells alone are unable to prevent completely the dissemination of infection in the body [154]. NK cell activation is regulated by integrated signals of several activating and suppressing receptors, many of which use major histocompatibility complex (MHC) class I molecules or related proteins as ligands. One of the cytotoxic NKactivating receptors is NKG2D. It was shown that CPXV and MPXV encode a protein resembling an MHC class I molecule (OMCP; C2 in CPXV-GRI) that blocks the recognition of host ligands and inhibits the NKG2D-dependent NK lysis of infected cells [155]. VARV and VACV genomes lack such a gene (Table 4 ).

As noted above, orthopoxviruses produce a secreted IL18-binding protein, which blocks not only the proinflammatory activity of IL-18 but also IL-18 induced NK cytotoxicity $[126,156]$.

Adaptive immune response to infection involves complex cytokine-regulated interactions among different types of cells [157] that give rise to B-lymphocytes producing virusspecific antibodies and virus-specific cytolytic $\mathrm{T}$ lymphocytes. Proliferation of virus-specific cytolytic T lymphocytes 
peaks on days 5-6 of infection; the key regulatory cytokines TNF, IL- $1 \beta$, and $\gamma$-IFN control not only inflammatory reactions but also the adaptive immune response. Specific antibodies can interact with virus particles and their components individually or within complement complexes. Specific antibodies are inefficient in controlling primary poxvirus infection but can be important in preventing secondary infection [154]. Cellular immune response is a crucial component of specific defense against a poxvirus infection [158].

For some orthopoxviruses, it has been shown that they directly infect human and rodent immune cells both in vitro and in vivo, including lymphocytes, NK cells, and monocytes/macrophages and VACV decrease antigen presentation in several types of antigen-presenting cells (APC) [159]. Recently, it was revealed that VACV-COP protein A35 inhibits MHC class II-restricted antigen presentation, immune priming of T lymphocytes, and subsequent cytokine and chemokine synthesis [160]. The gene of this protein is highly conservative for VACV, CPXV, and MPXV but in the genome of VARV is disrupted (see Table 4). Interestingly, for VACV MVA strain it was shown that deletion of the $A 35 R$ gene increases its immunogenicity [161]. In this respect, it should be noted known data that the persons that had smallpox acquire a lifelong immunity, whereas the vaccination with VACV requires repeated immunizations with a certain periodicity to provide a reliable protection against smallpox [10]. We may speculate that VARV nonfunctional short $A 38 R$ originated as a result of mutational changes in functional $A 35 R$ analog of ancestral zoonotic orthopoxvirus and it allowed to highly virulent VARV caused lifelong immunity in humans and provided the additional conditions for smallpox endemization [4].

MHC class I molecules play an important role in antiviral immunity. The majority of MHC class I-binding peptides are generated in the cytosol by proteasomes and transported into the lumen of the endoplasmic reticulum (ER) by transporter associated with antigen processing (TAP). Peptide loading onto the MHC class I heavy chain- $\beta 2 \mathrm{~m}$ heterodimer is facilitated by a multi-subunit protein complex called the MHC class I peptide-loading complex (PLC). In addition to TAP and MHC class I, the PLC is composed of ER chaperones. Upon peptide loading, the fully assembled MHC class I complexes dissociate from the PLC and transit to the cell surface. Recognition of viral peptides in the context of MHC class I molecules triggers virus-specific CD8 T cells to exert their effector functions including cytotoxicity and cytokine secretion [162].

Recently, it has been shown that CPXV downregulates MHC class I and evades antiviral CD8 T cell responses [163]. Two distinctly acting MHC class I regulating genes (D10L and B8R for CPXV-GRI, see Table 4) have been revealed. Protein D10 inhibits MHC class I expression by impairing ER peptide loading and dissociation of MHC class I from TAP. Protein B8 interferes with the intracellular trafficking of MHC class I molecules by sequestering them in the ER using its C-terminal KDEL-like sequence [162].

The in vivo significance of the discovered viral MHC class I and class II evasion mechanisms, however, is not well understood. Among orthopoxviruses pathogenic for humans only CPXV produces all three known regulators of MHC systems. Highly virulent and highly immunogenic for humans, VARV does not produce any of these proteins (Table 4).

\section{Conclusion}

Comparison of amino acid sequences of a great number of various types of human and rodent polypeptides revealed most pronounced interspecies differences in the sequences of the proteins forming ligand-receptor pairs of the organismal protective systems of these mammals against infectious agents. In addition, the polypeptide ligands and their receptors proved to be subjected to coevolution [164]. Pathogenic microorganisms are assumed to be able to cause an accelerated evolution of the defense system proteins (genes) of infected animal species. Such evolutionary changes in the primary structure of the proteins constituting ligandreceptor pairs were suggested to result in alterations of the quaternary structure of the ligand-receptor contact region $[164,165]$. As a result, the species-specific mimicry of mammalian defense system proteins may emerge, providing a narrower range of hosts sensitive to certain infectious microorganism [164].

The virus that maintains the balance between its pathogenic effect on the host organism and the possibility of its effective development in the animal organism for a relatively long period is the best adapted from the evolutionary standpoint. Such virus is able to transmit efficiently from animal to animal under a low population density. Among orthopoxviruses, CPXV most pronouncedly displays such properties. It is worth noting that CPXV encodes the complete set of immunomodulatory (Table 4) as well as Bcl-2-like (Table 1), ankyrin-like (Table 2), and kelch-like (Table 3) proteins found in orthopoxviruses, whereas VARV, MPXV, and VACV each possess an incomplete speciesspecific subset of these genes.

The species- and strain-specific distinctions between VARV, MPXV, CPXV, and VACV DNAs are localized to the long variable terminal regions $[3,23,63,64,166-$ 168]. These distinctions comprise not only deletions in DNAs of the viruses compared relative one another but also rearrangements and nucleotide substitutions $[3,169]$. The determined sequences of viral DNAs allow for a comparative analysis of organization of the VARV, MPXV, CPXV, and VACV molecular pathogenicity factors, whose function was verified at various laboratories in experiments mainly with VACV, CPXV, and ECTV [3, 22, 56, 116, 120, 121, 154, 157].

The CPXV genome has the largest size as compared with the other orthopoxviruses and contains the complete set of all the genes characteristic of other viruses from the genus Orthopoxvirus (Tables 1, 2, 3, and 4). The fact that CPXV nonetheless does not display an increased virulence suggests that orthopoxviruses have a certain regulatory system(s). To describe this regulatory system, we earlier introduced the concept of buffer genes, whose role is to neutralize the negative effects developing in the body during infection [22]. Presumably, CPXV possesses the widest set of these 
genes as compared with VARV, MPXV, and VACV. The rest orthopoxvirus species have lost certain part of the genes with reference to CPXV. Note that VARV contains the shortest orthopoxviral genome and the least set of actual genes. This observation suggests that CPXV is most close to the ancestor of orthopoxviruses, while the rest species emerged later due to deletions, recombinations, and mutations $[3,5,6,169]$.

Humans are the only VARV host; hence, this virus is to a maximal degree adapted evolutionarily to overcome the human defense reactions, which develop in response to the infection. MPXV, CPXV, and VACV have wide host range, infecting first and foremost various rodents. Humans are sporadically infected by these viruses. Consequently, MPXV, CPXV, and VACV are adapted to interactions with the molecular defense reactions of mammals of various species $[3,4,11,13,19,21]$. As we can see from the above-mentioned in these review cases, studied immunomodulatory proteins of VARV, as a rule, more effectively inhibit activities of their human ligands as compared with other species of orthopoxviruses pathogenic for humans. We may speculate that it is one of the most likely reasons of high VARV virulence for humans.

The interaction network of cytokines and their receptors has been so far studied only to a first approximation, and many discoveries are still awaiting researchers in this direction. Orthopoxviruses can play an important role here.

Summing up the available data, we may infer that VARV and other orthopoxviruses possess an unexampled set of genes whose protein products efficiently modulate the manifold defense functions of the host organisms compared with the viruses from other families. It is likely that by the example of orthopoxviruses, it will be possible in the nearest future to trace the patterns of coevolution of the viral pathogenicity factors and mammalian systems providing defense against infectious agents. The research into application of immunomodulatory proteins of orthopoxviruses, and first and foremost, variola virus, as drugs also deserves attention.

\section{Acknowledgment}

This work was supported by the Russian Foundation for Basic Research (Grant 12-04-00110).

\section{References}

[1] V. A. K. Rathinam and K. A. Fitzgerald, "Innate immune sensing of DNA viruses," Virology, vol. 411, no. 2, pp. 153$162,2011$.

[2] K. A. Stoermer and T. E. Morrison, "Complement and viral pathogenesis," Virology, vol. 411, no. 2, pp. 362-373, 2011.

[3] S. N. Shchelkunov, S. S. Marennikova, and R. W. Moyer, Orthopoxviruses Pathogenic for Humans, Springer, Berlin, Germany, 2005.

[4] S. N. Shchelkunov, "Emergence and reemergence of smallpox: the need in development of a new generation smallpox vaccine," Vaccine, vol. 29, supplement 4, pp. D49-D53, 2011.

[5] S. N. Shchelkunov, "How long ago did smallpox virus emerge?” Archives of Virology, vol. 154, no. 12, pp. 1865-1871, 2009.
[6] I. V. Babkin and S. N. Shchelkunov, "Time scale of poxvirus evolution," Molecular Biology, vol. 40, no. 1, pp. 16-19, 2006.

[7] B. Moss et al., "Poxviridae: the viruses and their replication," in Fields Virology, D. M. Knipe, P. M. Howley, D. E. Griffin et al., Eds., pp. 2905-2946, Lippincott Williams and Wilkins, Philadelphia, Pa, USA, 2007.

[8] D. J. Esteban and R. M. L. Buller, "Ectromelia virus: the causative agent of mousepox," Journal of General Virology, vol. 86, no. 10, pp. 2645-2659, 2005.

[9] J. L. Chapman, D. K. Nichols, M. J. Martinez, and J. W. Raymond, "Animal models of orthopoxvirus infection," Veterinary Pathology, vol. 47, no. 5, pp. 852-870, 2010.

[10] F. Fenner, D. A. Henderson, I. Arita, Z. Jezek, and I. D. Ladnyi, Smallpox and Its Eradication, World Health Organization, Geneva, Switzerland, 1988.

[11] J. G. Breman, "Monkeypox: an emerging infection of humans?" in Emerging Infections 4, W. M. Scheid, W. A. Craig, and J. M. Hughes, Eds., pp. 45-67, ASM Press, Washington, DC, USA, 2000.

[12] A. W. Rimoin, P. M. Mulembakani, S. C. Johnston et al., "Major increase in human monkeypox incidence 30 years after smallpox vaccination campaigns cease in the Democratic Republic of Congo," Proceedings of the National Academy of Sciences of the United States of America, vol. 107, no. 37, pp. 16262-16267, 2010.

[13] R. M. Vorou, V. G. Papavassiliou, and I. N. Pierroutsakos, "Cowpox virus infection: an emerging health threat," Current Opinion in Infectious Diseases, vol. 21, no. 2, pp. 153-156, 2008.

[14] H. Campe, P. Zimmermann, K. Glos et al., "Cowpox virus transmission from pet rats to humans, Germany," Emerging Infectious Diseases, vol. 15, no. 5, pp. 777-780, 2009.

[15] L. Ninove, Y. Domart, C. Vervel et al., "Cowpox virus transmission from pet rats to humans, France," Emerging Infectious Diseases, vol. 15, no. 5, pp. 781-784, 2009.

[16] S. Blackford, D. L. Roberts, and P. D. Thomas, "Cowpox infection causing a generalized eruption in a patient with atopic dermatitis," British Journal of Dermatology, vol. 129, no. 5, pp. 628-629, 1993.

[17] P. M. Pelkonen, K. Tarvainen, A. Hynninen et al., "Cowpox with severe generalized eruption, Finland," Emerging Infectious Diseases, vol. 9, no. 11, pp. 1458-1461, 2003.

[18] C. P. Czerny, A. M. Eis-Hübinger, A. Mayr, K. E. Schneweis, and B. Pfeiff, "Animal poxviruses transmitted from cat to man: current event with lethal end," Zentralblatt fur Veterinarmedizin B, vol. 38, no. 6, pp. 421-431, 1991.

[19] R. K. Singh, M. Hosamani, V. Balamurugan, V. Bhanuprakash, T. J. Rasool, and M. P. Yadav, "Buffalopox: an emerging and re-emerging zoonosis," Animal Health Research Reviews, vol. 8, no. 1, pp. 105-114, 2007.

[20] A. T. Silva-Fernandes, C. E. P. F. Travassos, J. M. S. Ferreira et al., "Natural human infections with vaccinia virus during bovine vaccinia outbreaks," Journal of Clinical Virology, vol. 44, no. 4, pp. 308-313, 2009.

[21] J. S. Abrahão, M. I. M. Guedes, G. S. Trindade et al., "One more piece in the VACV ecological puzzle: could peridomestic rodents be the link between wildlife and bovine vaccinia outbreaks in Brazil?" PLoS ONE, vol. 4, no. 10, Article ID e7428, 2009.

[22] S. N. Shchelkunov, "Functional organization of variola major and vaccinia virus genomes," Virus Genes, vol. 10, no. 1, pp. 53-71, 1995.

[23] S. N. Shchelkunov, P. F. Safronov, A. V. Totmenin et al., "The genomic sequence analysis of the left and right 
species-specific terminal region of a cowpox virus strain reveals unique sequences and a cluster of intact ORFs for immunomodulatory and host range proteins," Virology, vol. 243, no. 2, pp. 432-460, 1998.

[24] T. Kawai and S. Akira, "The role of pattern-recognition receptors in innate immunity: update on toll-like receptors," Nature Immunology, vol. 11, no. 5, pp. 373-384, 2010.

[25] M. Lamkanfi and V. M. Dixit, "The inflammasomes," PLoS Pathogens, vol. 5, no. 12, Article ID e1000510, 2009.

[26] A. A. Abdul-Sater, N. Saïd-Sadier, D. M. Ojcius, O. Yilmaz, and K. A. Kelly, "Inflammasomes bridge signaling between pathogen identification and the immune response," Drugs of Today, vol. 45, pp. 105-112, 2009.

[27] J. H. Pedra, S. L. Cassel, and F. S. Sutterwala, "Sensing pathogens and danger signals by the inflammasome," Current Opinion in Immunology, vol. 21, no. 1, pp. 10-16, 2009.

[28] A. Bowie, E. Kiss-Toth, J. A. Symons, G. L. Smith, S. K. Dower, and L. A. J. O'Neill, "A46R and A52R from vaccinia virus are antagonists of host IL-1 and toll-like receptor signaling," Proceedings of the National Academy of Sciences of the United States of America, vol. 97, no. 18, pp. 10162-10167, 2000.

[29] M. T. Harte, I. R. Haga, G. Maloney et al., "The poxvirus protein A52R targets toll-like receptor signaling complexes to suppress host defense," Journal of Experimental Medicine, vol. 197, no. 3, pp. 343-351, 2003.

[30] J. Stack, I. R. Haga, M. Schröder et al., "Vaccinia virus protein A46R targets multiple Toll-like-interleukin-1 receptor adaptors and contributes to virulence," Journal of Experimental Medicine, vol. 201, no. 6, pp. 1007-1018, 2005.

[31] S. C. Graham, M. W. Bahar, S. Cooray et al., "Vaccinia virus proteins A52 and B14 share a Bcl-2-like fold but have evolved to inhibit Nf- $\kappa \mathrm{B}$ rather than apoptosis," PLoS Pathogens, vol. 4, no. 8, Article ID e1000128, 2008.

[32] J. M. Gonzlez and M. Esteban, "A poxvirus Bcl-2-like gene family involved in regulation of host immune response: sequence similarity and evolutionary history," Virology Journal, vol. 7, article 59, 2010.

[33] L. Unterholzner, R. P. Sumner, M. Baran et al., "Vaccinia virus protein C6 is a virulence factor that binds TBK-1 adaptor proteins and inhibits activation of IRF3 and IRF7," PLoS Pathogens, vol. 7, no. 9, Article ID 100224, 2011.

[34] C. M. de Motes, S. Cooray, H. Ren et al., "Inhibition of apoptosis and NF-êB activation by vaccinia protein $\mathrm{N} 1$ occur via distinct binding surfaces and make different contributions to virulence," PLoS Pathogens, vol. 7, no. 12, Article ID 100243, 2011.

[35] A. Ciechanover, "Intracellular protein degradation: from a vague idea thru the lysosome and the ubiquitin-proteasome system and onto human diseases and drug targeting," Experimental Biology and Medicine, vol. 231, no. 7, pp. 11971211, 2006.

[36] D. R. Bosu and E. T. Kipreos, "Cullin-RING ubiquitin ligases: global regulation and activation cycles," Cell Division, vol. 3, article e7, 2008.

[37] M. Hochstrasser, "Origin and function of ubiquitin-like proteins," Nature, vol. 458, no. 7237, pp. 422-429, 2009.

[38] E. T. Kipreos, L. E. Lander, J. P. Wing, W. W. He, and E. M. Hedgecock, "cul-1 is required for cell cycle exit in C. elegans and identifies a novel gene family," Cell, vol. 85, no. 6, pp. 829-839, 1996.

[39] C. A. P. Joazeiro and A. M. Weissman, "RING finger proteins: mediators of ubiquitin ligase activity," Cell, vol. 102, no. 5, pp. 549-552, 2000.
[40] E. T. Kipreos and M. Pagano, "The F-box protein family," Genome Biology, vol. 1, no. 5, pp. reviews3002-reviews 3002.7, 2000.

[41] J. Jin, T. Cardozo, R. C. Lovering, S. J. Elledge, M. Pagano, and J. W. Harper, "Systematic analysis and nomenclature of mammalian F-box proteins," Genes and Development, vol. 18, no. 21, pp. 2573-2580, 2004.

[42] L. Pintard, A. Willems, and M. Peter, "Cullin-based ubiquitin ligases: Cul3-BTB complexes join the family," The EMBO Journal, vol. 23, no. 8, pp. 1681-1687, 2004.

[43] P. J. Stogios, G. S. Downs, J. J. Jauhal, S. K. Nandra, and G. G. Privé, "Sequence and structural analysis of BTB domain proteins," Genome Biology, vol. 6, no. 10, article R82, 2005.

[44] M. Furukawa and Y. Xiong, "BTB protein keap1 targets antioxidant transcription factor Nrf2 for ubiquitination by the cullin 3-Roc1 ligase," Molecular and Cellular Biology, vol. 25, no. 1, pp. 162-171, 2005.

[45] G. Gao and H. Luo, "The ubiquitin-proteasome pathway in viral infections," Canadian Journal of Physiology and Pharmacology, vol. 84, no. 1, pp. 5-14, 2006.

[46] M. J. Edelmann and B. M. Kessler, "Ubiquitin and ubiquitinlike specific proteases targeted by infectious pathogens: emerging patterns and molecular principles," Biochimica et Biophysica Acta, vol. 1782, no. 12, pp. 809-816, 2008.

[47] H. A. Lindner, "Deubiquitination in virus infection," Virology, vol. 362, no. 2, pp. 245-256, 2007.

[48] P. Blanchette and P. E. Branton, "Manipulation of the ubiquitin-proteasome pathway by small DNA tumor viruses," Virology, vol. 384, no. 2, pp. 317-323, 2009.

[49] N. Tolonen, L. Doglio, S. Schleich, and J. Krijnse Locker, "Vaccinia virus DNA replication occurs in endoplasmic reticulum-enclosed cytoplasmic mini-nuclei," Molecular Biology of the Cell, vol. 12, no. 7, pp. 2031-2046, 2001.

[50] A. Teale, S. Campbell, N. Van Buuren et al., "Orthopoxviruses require a functional ubiquitin-proteasome system for productive replication," Journal of Virology, vol. 83, no. 5, pp. 2099-2108, 2009.

[51] P. S. Satheshkumar, L. C. Anton, P. Sanz, and B. Moss, "Inhibition of the ubiquitin-proteasome system prevents vaccinia virus dna replication and expression of intermediate and late genes," Journal of Virology, vol. 83, no. 6, pp. 24692479, 2009.

[52] C. S. Chung, C. H. Chen, M. Y. Ho, C. Y. Huang, C. L. Liao, and W. Chang, "Vaccinia virus proteome: identification of proteins in vaccinia virus intracellular mature virion particles," Journal of Virology, vol. 80, no. 5, pp. 2127-2140, 2006.

[53] R. B. Luftig, "Does the cytoskeleton play a significant role in animal virus replication?" Journal of Theoretical Biology, vol. 99, no. 1, pp. 173-191, 1982.

[54] A. Schepis, B. Schramm, C. A. M. de Haan, and J. K. Locker, "Vaccinia virus-induced microtubule-dependent cellular rearrangements," Traffic, vol. 7, no. 3, pp. 308-323, 2006.

[55] P. M. Steinert and D. R. Roop, "Molecular and cellular biology of intermediate filaments," Annual Review of Biochemistry, vol. 57, pp. 593-625, 1988.

[56] F. Fenner, R. Wittek, and K. R. Dumbell, The Orthopoxviruses, Academic Press, New York, NY, USA, 1989.

[57] M. S. Hayden and S. Ghosh, "Shared principles in NF- $\kappa$ B signaling," Cell, vol. 132, no. 3, pp. 344-362, 2008.

[58] S. J. Chang, J. C. Hsiao, S. Sonnberg et al., "Poxvirus host range protein CP77 contains an F-box-like domain that is necessary to suppress NF- $\kappa \mathrm{B}$ activation by tumor necrosis 
factor alpha but is independent of its host range function," Journal of Virology, vol. 83, no. 9, pp. 4140-4152, 2009.

[59] J. L. Shisler and X. L. Jin, "The vaccinia virus K1L gene product inhibits host NF- $\kappa \mathrm{B}$ activation by preventing $\mathrm{I} \kappa \mathrm{B} \alpha$ degradation," Journal of Virology, vol. 78, no. 7, pp. 35533560, 2004.

[60] S. E. Lux, K. M. John, and V. Bennett, "Analysis of cDNA for human erythrocyte ankyrin indicates a repeated structure with homology to tissue-differentiation and cell-cycle control proteins," Nature, vol. 344, no. 6261, pp. 36-42, 1990.

[61] S. Lambert, H. Yu, J. T. Prchal et al., "cDNA sequence for human erythrocyte ankyrin," Proceedings of the National Academy of Sciences of the United States of America, vol. 87, no. 5, pp. 1730-1734, 1990.

[62] S. N. Shchelkunov, V. M. Blinov, and L. S. Sandakhchiev, "Ankyrin-like proteins of variola and vaccinia viruses," FEBS Letters, vol. 319, no. 1-2, pp. 163-165, 1993.

[63] S. N. Shchelkunov, "Interaction of orthopoxviruses with the cellular ubiquitin-ligase system," Virus Genes, vol. 41, no. 3, pp. 309-318, 2010.

[64] S. N. Shchelkunov, A. V. Totmenin, I. V. Babkin et al., "Human monkeypox and smallpox viruses: genomic comparison," FEBS Letters, vol. 509, no. 1, pp. 66-70, 2001.

[65] C. Meisinger-Henschel, M. Schmidt, S. Lukassen et al., "Genomic sequence of chorioallantois vaccinia virus Ankara, the ancestor of modified vaccinia virus Ankara," Journal of General Virology, vol. 88, no. 12, pp. 3249-3259, 2007.

[66] A. A. Mercer, S. B. Fleming, and N. Ueda, "F-box-like domains are present in most poxvirus ankyrin repeat proteins," Virus Genes, vol. 31, no. 2, pp. 127-133, 2005.

[67] S. Sonnberg, B. T. Seet, T. Pawson, S. B. Fleming, and A. A. Mercer, "Poxvirus ankyrin repeat proteins are a unique class of F-box proteins that associate with cellular SCF1 ubiquitin ligase complexes," Proceedings of the National Academy of Sciences of the United States of America, vol. 105, no. 31, pp. 10955-10960, 2008.

[68] S. Sonnberg, S. B. Fleming, and A. A. Mercer, "A truncated two- $\alpha$-helix F-box present in poxvirus ankyrin-repeat proteins is sufficient for binding the SCF1 ubiquitin ligase complex," Journal of General Virology, vol. 90, no. 5, pp. 1224-1228, 2009.

[69] M. R. Mohamed, M. M. Rahman, J. S. Lanchbury et al., "Proteomic screening of variola virus reveals a unique NF$\kappa \mathrm{B}$ inhibitor that is highly conserved among pathogenic orthopoxviruses," Proceedings of the National Academy of Sciences of the United States of America, vol. 106, no. 22, pp. 9045-9050, 2009.

[70] K. M. Sperling, A. Schwantes, C. Staib, B. S. Schnierle, and G. Sutter, "The orthopoxvirus 68-kilodalton ankyrin-like protein is essential for DNA replication and complete gene expression of modified vaccinia virus ankara in nonpermissive human and murine cells," Journal of Virology, vol. 83, no. 12, pp. 6029-6038, 2009.

[71] N. van Buuren, B. Couturier, Y. Xiong, and M. Barry, "Ectromelia virus encodes a novel family of F-box proteins that interact with the SCF complex," Journal of Virology, vol. 82, no. 20, pp. 9917-9927, 2008.

[72] T. G. Senkevich, G. L. Muravnik, S. G. Pozdnyakov et al., "Nucleotide sequence of XhoI fragment of ectromelia virus DNA reveals significant differences from vaccinia virus," Virus Research, vol. 30, no. 1, pp. 73-88, 1993.

[73] S. N. Shchelkunov, V. M. Blinov, S. M. Resenchuk et al., "Analysis of the nucleotide sequence of $53 \mathrm{kbp}$ from the right terminus of the genome of variola major virus strain India1967," Virus Research, vol. 34, no. 3, pp. 207-236, 1994.

[74] S. Shchelkunov, A. Totmenin, and I. Kolosova, "Speciesspecific differences in organization of orthopoxvirus kelchlike proteins," Virus Genes, vol. 24, no. 2, pp. 157-162, 2002.

[75] N. Chen, M. I. Danila, Z. Feng et al., "The genomic sequence of ectromelia virus, the causative agent of mousepox," Virology, vol. 317, no. 1, pp. 165-186, 2003.

[76] M. E. Perkus, S. J. Goebel, S. W. Davis, G. P. Johnson, E. K. Norton, and E. Paoletti, "Deletion of 55 open reading frames from the termini of vaccinia virus," Virology, vol. 180, no. 1, pp. 406-410, 1991.

[77] B. A. Wilton, S. Campbell, N. Van Buuren et al., "Ectromelia virus BTB/kelch proteins, EVM150 and EVM167, interact with cullin-3-based ubiquitin ligases," Virology, vol. 374, no. 1, pp. 82-99, 2008.

[78] L. Zhang, N. Y. Villa, and G. McFadden, "Interplay between poxviruses and the cellular ubiquitin/ubiquitin-like pathways," FEBS Letters, vol. 583, no. 4, pp. 607-614, 2009.

[79] G. V. Kochneva, I. V. Kolosova, T. A. Lupan et al., "Orthopoxvirus genes for kelch-like proteins: III. Construction of mousepox (ectromelia) virus variants with targeted gene deletions," Molecular Biology, vol. 43, no. 4, pp. 567-572, 2009.

[80] G. Kochneva, I. Kolosova, T. Maksyutova, E. Ryabchikova, and S. Shchelkunov, "Effects of deletions of kelch-like genes on cowpox virus biological properties," Archives of Virology, vol. 150, no. 9, pp. 1857-1870, 2005.

[81] G. V. Kochneva, O. S. Taranov, T. A. Lupan et al., "Investigation of the impact of cowpox virus BTB/kelch gene deletion on some characteristics of infection in vitro," Voprosy Virusologii, vol. 54, no. 1, pp. 28-32, 2009.

[82] M. P. de Miranda, P. C. Reading, D. C. Tscharke, B. J. Murphy, and G. L. Smith, "The vaccinia virus kelch-like protein C2L affects calcium-independent adhesion to the extracellular matrix and inflammation in a murine intradermal model," Journal of General Virology, vol. 84, no. 9, pp. 2459-2471, 2003.

[83] P. M. Beard, G. C. Froggatt, and G. L. Smith, "Vaccinia virus kelch protein A55 is a $64 \mathrm{kDa}$ intracellular factor that affects virus-induced cytopathic effect and the outcome of infection in a murine intradermal model," Journal of General Virology, vol. 87, no. 6, pp. 1521-1529, 2006.

[84] G. C. Froggatt, G. L. Smith, and P. M. Beard, "Vaccinia virus gene $\mathrm{F} 3 \mathrm{~L}$ encodes an intracellular protein that affects the innate immune response," Journal of General Virology, vol. 88, no. 7, pp. 1917-1921, 2007.

[85] J. F. Kerr, A. H. Wyllie, and A. R. Currie, "Apoptosis: a basic biological phenomenon with wide-ranging implications in tissue kinetics," British Journal of Cancer, vol. 26, no. 4, pp. 239-257, 1972.

[86] M. R. Hilleman, "Strategies and mechanisms for host and pathogen survival in acute and persistent viral infections," Proceedings of the National Academy of Sciences of the United States of America, vol. 101, supplement 2, pp. 14560-14566, 2004.

[87] E. Domingo-Gil and M. Esteban, "Role of mitochondria in apoptosis induced by the $2-5 \mathrm{~A}$ system and mechanisms involved," Apoptosis, vol. 11, no. 5, pp. 725-738, 2006.

[88] M. G. Netea, A. Simon, F. van de Veerdonk, B. J. Kullberg, J. W. M. van der Meer, and L. A. B. Joosten, "IL-1 $\beta$ processing in host defense: beyond the inflammasomes," PLoS Pathogens, vol. 6, no. 2, Article ID e1000661, 2010. 
[89] J. Macen, A. Takahashi, K. B. Moon, R. Nathaniel, P. C. Turner, and R. W. Moyer, "Activation of caspases in pig kidney cells infected with wild-type and CrmA/SPI-2 mutants of cowpox and rabbitpox viruses," Journal of Virology, vol. 72, no. 5, pp. 3524-3533, 1998.

[90] B. T. Seet, J. B. Johnston, C. R. Brunetti et al., "Poxviruses and immune evasion," Annual Review of Immunology, vol. 21, pp. 377-423, 2003.

[91] B. G. Luttge and R. W. Moyer, "Suppressors of a host range mutation in the rabbitpox virus serpin SPI-1 map to proteins essential for viral DNA replication," Journal of Virology, vol. 79, no. 14, pp. 9168-9179, 2005.

[92] J. M. Taylor, D. Quilty, L. Banadyga, and M. Barry, "The vaccinia virus protein F1L interacts with Bim and inhibits activation of the pro-apoptotic protein Bax," Journal of Biological Chemistry, vol. 281, no. 51, pp. 39728-39739, 2006.

[93] A. Postigo, M. C. Martin, M. P. Dodding, and M. Way, "Vaccinia-induced epidermal growth factor receptor-MEK signalling and the anti-apoptotic protein F1L synergize to suppress cell death during infection," Cellular Microbiology, vol. 11, no. 8, pp. 1208-1218, 2009.

[94] D. Zhai, E. Yu, C. Jin et al., "Vaccinia virus protein F1L is a caspase-9 inhibitor," Journal of Biological Chemistry, vol. 285, no. 8, pp. 5569-5580, 2010.

[95] M. Aoyagi, D. Zhai, C. Jin et al., "Vaccinia virus N1L protein resembles a B cell lymphoma-2 (Bcl-2) family protein," Protein Science, vol. 16, no. 1, pp. 118-124, 2007.

[96] C. Gubser, D. Bergamaschi, M. Hollinshead, X. Lu, F. J. van Kuppeveld, and G. L. Smith, "A new inhibitor of apoptosis from vaccinia virus and eukaryotes," PLoS Pathogens, vol. 3, no. 2, article e17, 2007.

[97] P. Zhang, J. O. Langland, B. L. Jacobs, and C. E. Samuel, “Protein kinase PKR-dependent activation of mitogen-activated protein kinases occurs through mitochondrial adapter IPS-1 and is antagonized by vaccinia virus E3L," Journal of Virology, vol. 83, no. 11, pp. 5718-5725, 2009.

[98] T. G. Senkevich, E. V. Koonin, and R. M. L. Buller, "A poxvirus protein with a RING zinc finger motif is of crucial importance for virulence," Virology, vol. 198, no. 2, pp. 118 128, 1994.

[99] T. G. Senkevich, E. J. Wolffe, and R. M. L. Buller, "Ectromelia virus RING finger protein is localized in virus factories and is required for virus replication in macrophages," Journal of Virology, vol. 69, no. 7, pp. 4103-4111, 1995.

[100] J. Huang, Q. Huang, X. Zhou et al., "The poxvirus p28 virulence factor is an E3 ubiquitin ligase," Journal of Biological Chemistry, vol. 279, no. 52, pp. 54110-54116, 2004.

[101] C. E. Samuel, "Antiviral actions of interferon interferonregulated cellular proteins and their surprisingly selective antiviral activities," Virology, vol. 183, no. 1, pp. 1-11, 1991.

[102] N. L. Varich, I. V. Sychova, and N. V. Kaverin, "Transcription of both DNA strands of vaccinia virus genome in vivo," Virology, vol. 96, no. 2, pp. 412-420, 1979.

[103] P. Whitaker-Dowling and J. S. Youngner, "Characterization of a specific kinase inhibitory factor produced by vaccinia virus which inhibits the interferon-induced protein kinase," Virology, vol. 137, no. 1, pp. 171-181, 1984.

[104] J. C. Watson, H. W. Chang, and B. L. Jacobs, "Characterization of a vaccinia virus-encoded double-stranded RNAbinding protein that may be involved in inhibition of the double-stranded RNA-dependent protein kinase," Virology, vol. 185, no. 1, pp. 206-216, 1991.

[105] M. V. Davies, H. W. Chang, B. L. Jacobs, and R. J. Kaufman, "The E3L and K3L vaccinia virus gene products stimulate translation through inhibition of the double-stranded RNAdependent protein kinase by different mechanisms," Journal of Virology, vol. 67, no. 3, pp. 1688-1692, 1993.

[106] E. Beattie, J. Tartaglia, and E. Paoletti, "Vaccinia virusencoded eIF- $2 \alpha$ homolog abrogates the antiviral effect of interferon," Virology, vol. 183, no. 1, pp. 419-422, 1991.

[107] P. R. Romano, F. Zhang, S. L. Tan et al., "Inhibition of doublestranded RNA-dependent protein kinase PKR by vaccinia virus E3: role of complex formation and the E3 N-terminal domain," Molecular and Cellular Biology, vol. 18, no. 12, pp. 7304-7316, 1998.

[108] T. A. Brandt and B. L. Jacobs, "Both carboxy- and aminoterminal domains of the vaccinia virus interferon resistance gene, E3L, are required for pathogenesis in a mouse model," Journal of Virology, vol. 75, no. 2, pp. 850-856, 2001.

[109] H. W. Chang, J. C. Watson, and B. L. Jacobs, "The E3L gene of vaccinia virus encodes an inhibitor of the interferoninduced, double-stranded RNA-dependent protein kinase," Proceedings of the National Academy of Sciences of the United States of America, vol. 89, no. 11, pp. 4825-4829, 1992.

[110] C. Rivas, J. Gil, Z. Mělková, M. Esteban, and M. Díaz-Guerra, "Vaccinia virus E3L protein is an inhibitor of the interferon (IFN)- induced 2-5A synthetase enzyme," Virology, vol. 243, no. 2, pp. 406-414, 1998.

[111] S. N. Shchelkunov, A. V. Totmenin, P. F. Safronov et al., "Analysis of the monkeypox virus genome," Virology, vol. 297, no. 2, pp. 172-194, 2002.

[112] P. Bandi, N. E. Pagliaccetti, and M. D. Robek, "Inhibition of type III interferon activity by orthopoxvirus immunomodulatory proteins," Journal of Interferon and Cytokine Research, vol. 30, no. 3, pp. 123-133, 2010.

[113] B. A. Mann, J. H. Huang, P. Li et al., "Vaccinia virus blocks Stat1-dependent and Stat1-independent gene expression induced by type I and type II interferons," Journal of Interferon and Cytokine Research, vol. 28, no. 6, pp. 367-380, 2008.

[114] A. Alcami and G. L. Smith, "Vaccinia, cowpox, and camelpox viruses encode soluble gamma interferon receptors with novel broad species specificity," Journal of Virology, vol. 69, no. 8, pp. 4633-4639, 1995.

[115] J. A. Symons, A. Alcami, and G. L. Smith, "Vaccinia virus encodes a soluble type I interferon receptor of novel structure and broad species specificity," Cell, vol. 81, no. 4, pp. 551-560, 1995.

[116] S. N. Shchelkunov, "Immunomodulatory proteins of orthopoxviruses," Molecular Biology, vol. 37, no. 1, pp. 37-48, 2003.

[117] M. D. M. F. De Marco, A. Alejo, P. Hudson, I. K. Damon, and A. Alcami, "The highly virulent variola and monkeypox viruses express secreted inhibitors of type I interferon," The FASEB Journal, vol. 24, no. 5, pp. 1479-1488, 2010.

[118] K. J. Tracey and A. Cerami, "Tumor necrosis factor: a pleiotropic cytokine and therapeutic target," Annual Review of Medicine, vol. 45, pp. 491-503, 1994.

[119] G. J. Kotwal, "Microorganisms and their interaction with the immune system," Journal of Leukocyte Biology, vol. 62, no. 4, pp. 415-429, 1997.

[120] G. J. Kotwal, R. Blasco, C. G. Miller, S. Kuntz, S. Jayaraman, and S. N. Shchelkunov, "Strategies for immunomodulation and evasion by microbes: important consideration in the development of live vaccines," in Symposium in Immunology VII, M. M. Eibl and C. Huber, Eds., pp. 25-47, Springer, Berlin, Germany, 1998. 
[121] A. Alcami and U. H. Koszinowski, "Viral mechanisms of immune evasion," Immunology Today, vol. 21, no. 9, pp. 447455, 2000.

[122] G. J. Palumbo, D. J. Pickup, T. N. Fredrickson, L. J. McIntyre, and R. M. L. Buller, "Inhibition of an inflammatory response is mediated by a $38-\mathrm{kD}$ a protein of cowpox virus," Virology, vol. 172, no. 1, pp. 262-273, 1989.

[123] G. J. Palumbo, W. C. Glasgow, and R. M. L. Buller, "Poxvirusinduced alteration of arachidonate metabolism," Proceedings of the National Academy of Sciences of the United States of America, vol. 90, no. 5, pp. 2020-2024, 1993.

[124] A. Alcami and G. L. Smith, "A soluble receptor for interleukin- $1 \beta$ encoded by vaccinia virus: a novel mechanism of virus modulation of the host response to infection," Cell, vol. 71, no. 1, pp. 153-167, 1992.

[125] A. Alcamí and G. L. Smith, "A mechanism for the inhibition of fever by a virus," Proceedings of the National Academy of Sciences of the United States of America, vol. 93, no. 20, pp. 11029-11034, 1996.

[126] T. L. Born, L. A. Morrison, D. J. Esteban et al., "A poxvirus protein that binds to and inactivates IL-18, and inhibits NK cell response," Journal of Immunology, vol. 164, no. 6, pp. 3246-3254, 2000.

[127] S. N. Shchelkunov, V. M. Blinov, and L. S. Sandakhchiev, "Genes of variola and vaccinia viruses necessary to overcome the host protective mechanisms," FEBS Letters, vol. 319, no. $1-2$, pp. 80-83, 1993.

[128] C. Upton, J. L. Macen, M. Schreiber, and G. McFadden, "Myxoma virus expresses a secreted protein with homology to the tumor necrosis factor receptor gene family that contributes to viral virulence," Virology, vol. 184, no. 1, pp. 370-382, 1991.

[129] C. A. Smith, F. Q. Hu, T. Davis Smith et al., "Cowpox virus genome encodes a second soluble homologue of cellular TNF receptors, distinct from CrmB, that binds TNF but not LT $\alpha$," Virology, vol. 223, no. 1, pp. 132-147, 1996.

[130] V. N. Loparev, J. M. Parsons, J. C. Knight et al., "A third distinct tumor necrosis factor receptor of orthopoxviruses," Proceedings of the National Academy of Sciences of the United States of America, vol. 95, no. 7, pp. 3786-3791, 1998.

[131] A. Saraiva and A. Alcami, "CrmE, a novel soluble tumor necrosis factor receptor encoded by poxviruses," Journal of Virology, vol. 75, no. 1, pp. 226-233, 2001.

[132] I. P. Gileva, I. A. Ryazankin, Z. A. Maksyutov et al., "Comparative assessment of the properties of orthopoxviral soluble receptors for tumor necrosis factor," Doklady Biochemistry and Biophysics, vol. 390, pp. 160-164, 2003.

[133] I. P. Gileva, T. S. Nepomnyashchikh, D. V. Antonets et al., "Properties of the recombinant TNF-binding proteins from variola, monkeypox, and cowpox viruses are different," Biochimica et Biophysica Acta, vol. 1764, no. 11, pp. 17101718, 2006.

[134] A. Alejo, M. B. Ruiz-Argüello, Y. Ho, V. P. Smith, M. Saraiva, and A. Alcami, "A chemokine-binding domain in the tumor necrosis factor receptor from variola (smallpox) virus," Proceedings of the National Academy of Sciences of the United States of America, vol. 103, no. 15, pp. 5995-6000, 2006.

[135] D. V. Antonets, T. S. Nepomnyashchikh, and S. N. Shchelkunov, "SECRET domain of variola virus CrmB protein can be a member of poxviral type II chemokinebinding proteins family," BMC Research Notes, vol. 3, article e271, 2010.
[136] B. J. Rollins, “Chemokines," Blood, vol. 90, no. 3, pp. 909-928, 1997.

[137] A. H. Patel, D. F. Gaffney, J. H. Subak-Sharpe, and N. D. Stow, "DNA sequence of the gene encoding a major secreted protein of vaccinia virus, strain Lister," Journal of General Virology, vol. 71, no. 9, pp. 2013-2021, 1990.

[138] C. A. Smith, T. D. Smith, P. J. Smolak et al., "Poxvirus genomes encode a secreted, soluble protein that preferentially inhibits $\mathrm{P}$ chemokine activity yet lacks sequence homology to known chemokine receptors," Virology, vol. 236, no. 2, pp. 316-327, 1997.

[139] M. W. Bahar, J. C. Kenyon, M. M. Putz et al., "Structure and function of A41, a vaccinia virus chemokine binding protein," PLoS Pathogens, vol. 4, no. 1, article e5, 2008.

[140] M. B. Ruiz-Argüello, V. P. Smith, G. S. V. Campanella et al., "An ectromelia virus protein that interacts with chemokines through their glycosaminoglycan binding domain," Journal of Virology, vol. 82, no. 2, pp. 917-926, 2008.

[141] S. V. Seregin, I. N. Babkina, A. E. Nesterov, A. N. Sinyakov, and S. N. Shchelkunov, "Comparative studies of gammainterferon receptor-like proteins of variola major and variola minor viruses," FEBS Letters, vol. 382, no. 1-2, pp. 79-83, 1996.

[142] C. Upton, K. Mossman, and G. McFadden, "Encoding of a homolog of the IFN- $\gamma$ receptor by myxoma virus," Science, vol. 258, no. 5086, pp. 1369-1372, 1992.

[143] K. Mossman, C. Upton, R. M. L. Buller, and G. McFadden, "Species specificity of ectromelia virus and vaccinia virus interferon- $\gamma$ binding proteins," Virology, vol. 208, no. 2, pp. 762-769, 1995.

[144] S. S. Marennikova and S. N. Shchelkunov, Orthopoxviruses Pathogenic for Humans, KMK Press, Moscow, Russia, 1998.

[145] G. J. Kotwal and B. Moss, "Vaccinia virus encodes a secretory polypeptide structurally related to complement control proteins," Nature, vol. 335, no. 6186, pp. 176-178, 1988.

[146] M. K. Liszewski and J. P. Atkinson, "Novel complement inhibitors," Expert Opinion on Investigational Drugs, vol. 7, no. 3, pp. 323-331, 1998.

[147] M. D. Kirkitadze, C. Henderson, N. C. Price et al., "Central modules of the vaccinia virus complement control protein are not in extensive contact," Biochemical Journal, vol. 344, no. 1, pp. 167-175, 1999.

[148] S. A. Smith, N. P. Mullin, J. Parkinson et al., "Conserved surface-exposed K/R-X-K/R motifs and net positive charge on poxvirus complement control proteins serve as putative heparin binding sites and contribute to inhibition of molecular interactions with human endothelial cells: a novel mechanism for evasion of host defense," Journal of Virology, vol. 74, no. 12, pp. 5659-5666, 2000.

[149] C. G. Miller, S. N. Shchelkunov, and G. J. Kotwal, "The cowpox virus-encoded homolog of the vaccinia virus complement control protein is an inflammation modulatory protein," Virology, vol. 229, no. 1, pp. 126-133, 1997.

[150] J. Howard, D. E. Justus, A. V. Totmenin, S. Shchelkunov, and G. J. Kotwal, "Molecular mimicry of the inflammation modulatory proteins (IMPS) of poxviruses: evasion of the inflammatory response to preserve viral habitat," Journal of Leukocyte Biology, vol. 64, no. 1, pp. 68-71, 1998.

[151] E. A. Uvarova and S. N. Shchelkunov, "Species-specific differences in the structure of orthopoxvirus complementbinding protein," Virus Research, vol. 81, no. 1-2, pp. 39-45, 2001.

[152] A. M. Rosengard, Y. Liu, Z. Nie, and R. Jimenez, "Variola virus immune evasion design: expression of a highly efficient 
inhibitor of human complement," Proceedings of the National Academy of Sciences of the United States of America, vol. 99, no. 13, pp. 8808-8813, 2002.

[153] S. Jonjic, M. Babic, B. Polic, and A. Krmpotic, "Immune evasion of natural killer cells by viruses," Current Opinion in Immunology, vol. 20, no. 1, pp. 30-38, 2008.

[154] R. M. L. Buller and G. J. Palumbo, "Poxvirus pathogenesis," Microbiological Reviews, vol. 55, no. 1, pp. 80-122, 1991.

[155] J. A. Campbell, D. S. Trossman, W. M. Yokoyama, and L. N. Carayannopoulos, "Zoonotic orthopoxviruses encode a high-affinity antagonist of NKG2D," Journal of Experimental Medicine, vol. 204, no. 6, pp. 1311-1317, 2007.

[156] H. Okamura, H. Tsutsui, S. I. Kashiwamura, T. Yoshimoto, and K. Nakanishi, "Interleukin-18: a novel cytokine that augments both innate and acquired immunity," Advances in Immunology, vol. 70, pp. 281-312, 1998.

[157] M. K. Spriggs, "One step ahead of the game: viral immunomodulatory molecules," Annual Review of Immunology, vol. 14, pp. 101-130, 1996.

[158] W. E. Demkowicz and F. A. Ennis, "Vaccinia virus-specific $\mathrm{CD}^{+}$cytotoxic T lymphocytes in humans," Journal of Viro$\log y$, vol. 67, no. 3, pp. 1538-1544, 1993.

[159] K. E. Rehm, R. F. Connor, G. J. B. Jones, K. Yimbu, M. D. Mannie, and R. L. Roper, "Vaccinia virus decreases major histocompatibility complex (MHC) class II antigen presentation, T-cell priming, and peptide association with MHC class II," Immunology, vol. 128, no. 3, pp. 381-392, 2009.

[160] K. E. Rehm, R. F. Connor, G. J. B. Jones, K. Yimbu, and R. L. Roper, "Vaccinia virus A35R inhibits MHC class II antigen presentation," Virology, vol. 397, no. 1, pp. 176-186, 2010.

[161] K. E. Rehm and R. L. Roper, "Deletion of the A35 gene from modified vaccinia virus Ankara increases immunogenicity and isotype switching," Vaccine, vol. 29, no. 17, pp. 3276$3283,2011$.

[162] M. Byun, M. C. Verweij, D. J. Pickup, E. J. H. J. Wiertz, T. H. Hansen, and W. M. Yokoyama, "Two mechanistically distinct immune evasion proteins of cowpox virus combine to avoid antiviral CD8 T cells," Cell Host and Microbe, vol. 6, no. 5, pp. 422-432, 2009.

[163] A. Dasgupta, E. Hammarlund, M. K. Slifka, and K. Früh, "Cowpox virus evades CTL recognition and inhibits the intracellular transport of MHC class I molecules," Journal of Immunology, vol. 178, no. 3, pp. 1654-1661, 2007.

[164] P. M. Murphy, "Molecular mimicry and the generation of host defense protein diversity," Cell, vol. 72, no. 6, pp. 823826, 1993.

[165] B. Beutler and C. van Huffel, "An evolutionary and functional approach to the TNF receptor/ligand family," Annals of the New York Academy of Sciences, vol. 730, pp. 118-133, 1994.

[166] S. N. Shchelkunov, R. F. Massung, and J. J. Esposito, "Comparison of the genome DNA sequences of Bangladesh-1975 and India-1967 variola viruses," Virus Research, vol. 36, no. 1, pp. 107-118, 1995.

[167] R. F. Massung, V. N. Loparev, J. C. Knight et al., "Terminal region sequence variations in variola virus DNA," Virology, vol. 221, no. 2, pp. 291-300, 1996.

[168] S. N. Shchelkunov, A. V. Totmenin, V. N. Loparev et al., "Alastrim smallpox variola minor virus genome DNA sequences," Virology, vol. 266, no. 2, pp. 361-386, 2000.

[169] S. N. Shchelkunov and A. V. Totmenin, "Two types of deletions in orthopoxvirus genomes," Virus Genes, vol. 9, no. 3, pp. 231-245, 1995. 

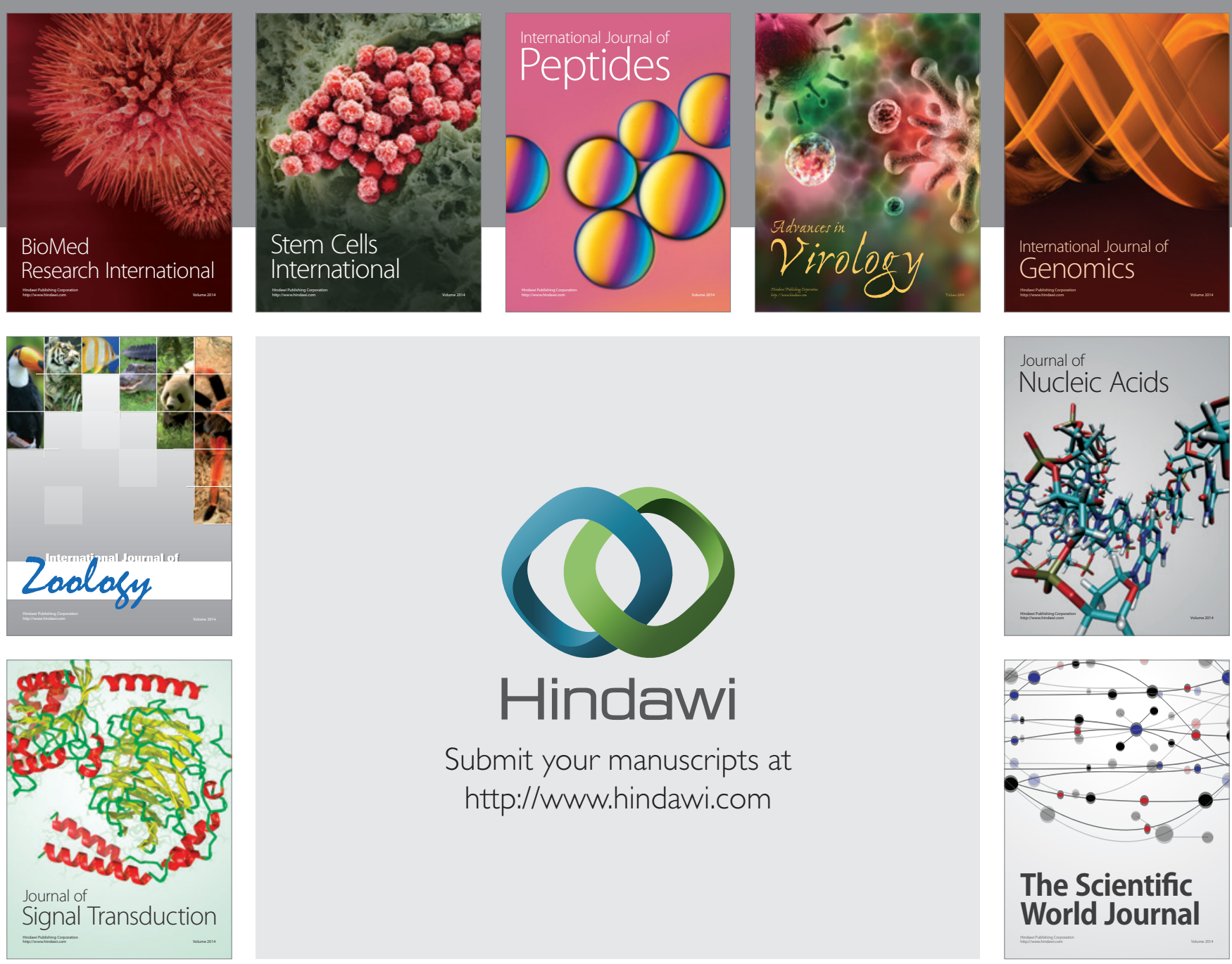

Submit your manuscripts at

http://www.hindawi.com
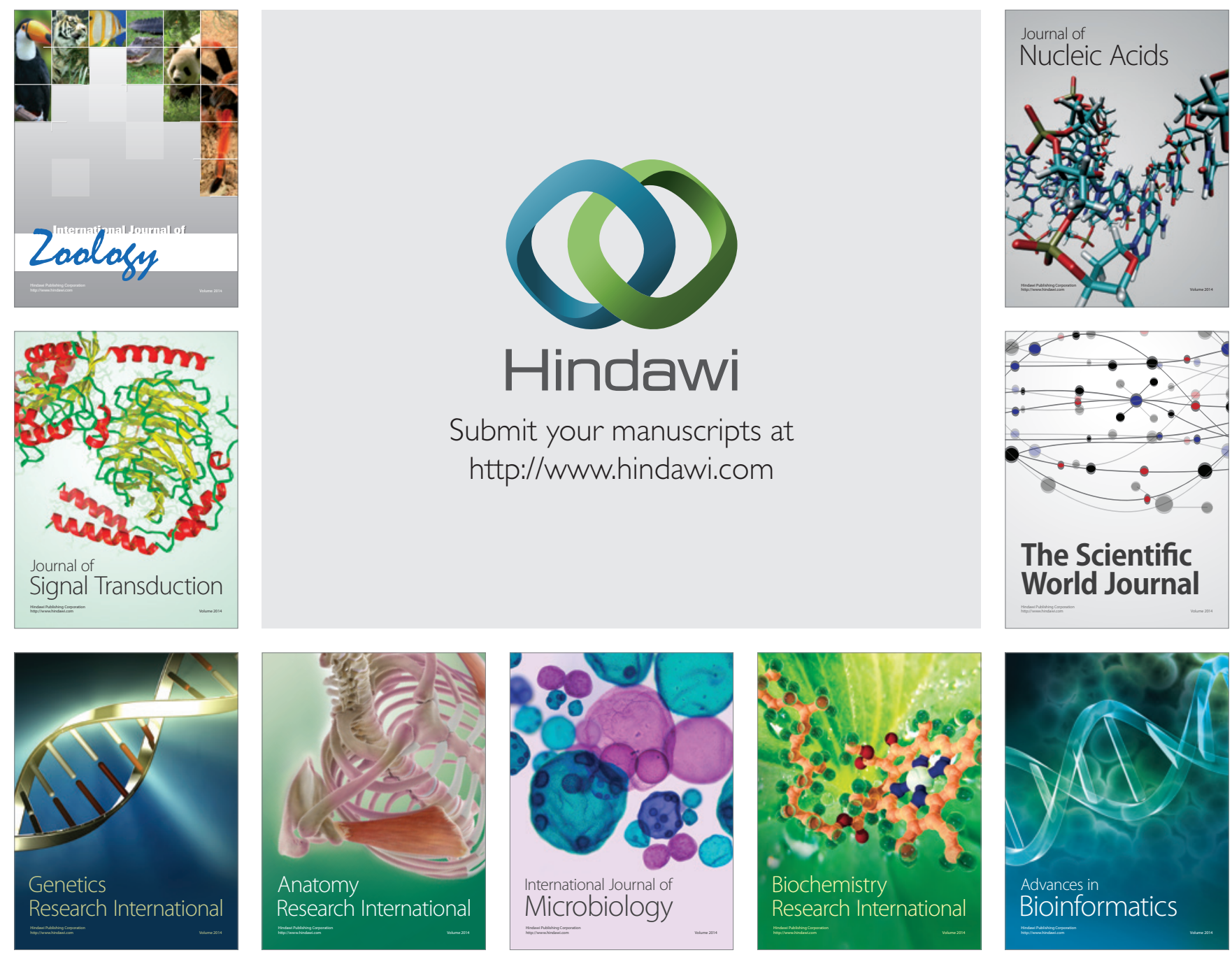

The Scientific World Journal
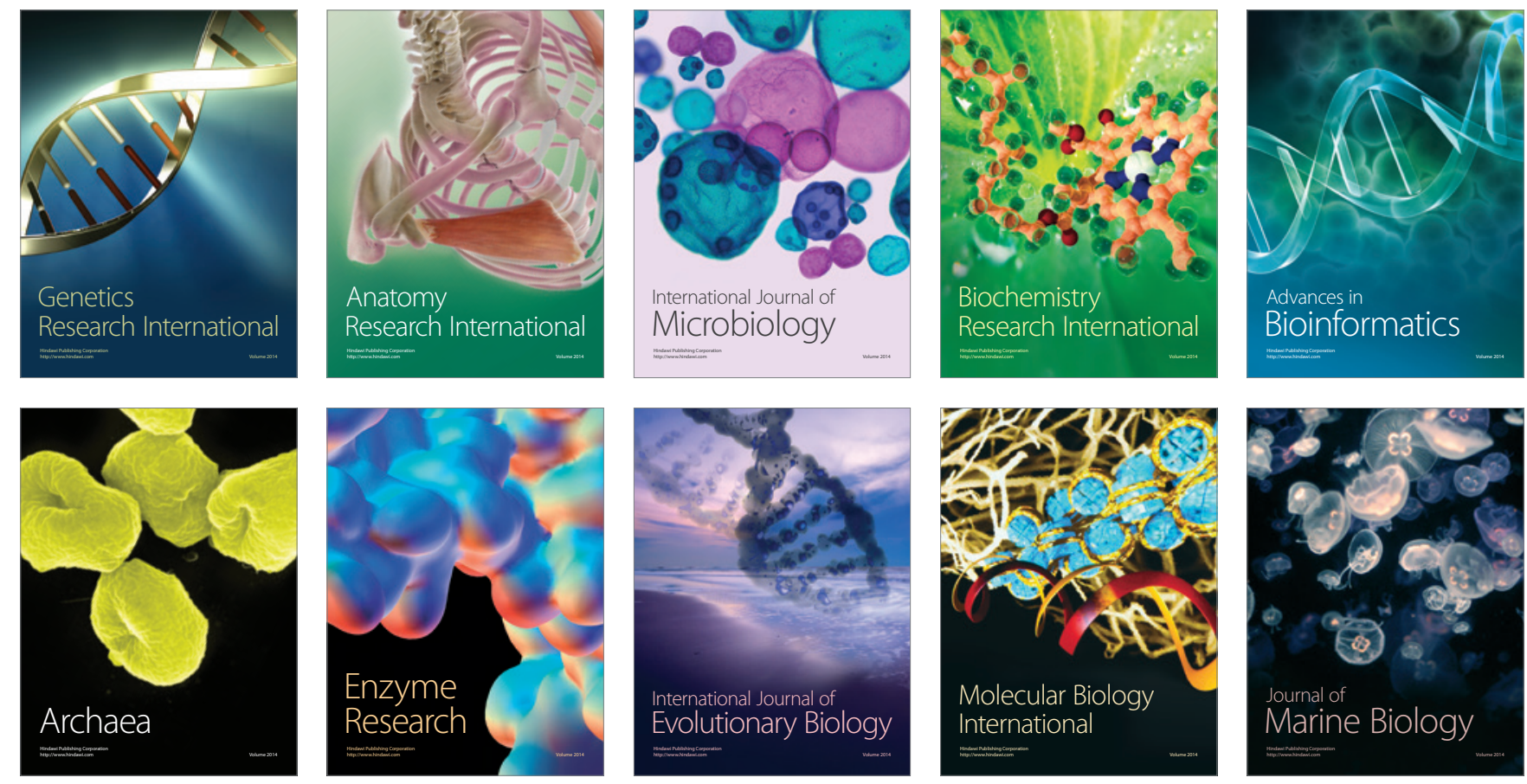